Portland State University

PDXScholar

$1-1-2011$

\title{
Molecular Genetic Analysis of CRELD1 in Patients with Heterotaxy Disorder
}

Samaneh Zhian

Portland State University

Follow this and additional works at: https://pdxscholar.library.pdx.edu/open_access_etds

Part of the Biology Commons

Let us know how access to this document benefits you.

\section{Recommended Citation}

Zhian, Samaneh, "Molecular Genetic Analysis of CRELD1 in Patients with Heterotaxy Disorder" (2011). Dissertations and Theses. Paper 410.

https://doi.org/10.15760/etd.410

This Thesis is brought to you for free and open access. It has been accepted for inclusion in Dissertations and Theses by an authorized administrator of PDXScholar. Please contact us if we can make this document more accessible: pdxscholar@pdx.edu. 
Molecular Genetic Analysis of CRELD1 in Patients with Heterotaxy Disorder

by

Samaneh Zhian

A thesis submitted in partial fulfillment of the requirements for the degree of

\author{
Master of Science \\ in \\ Biology
}

Thesis Committee:

Deborah Duffield, Chair

Cheryl Maslen

Suzanne Estes

Portland State University

(C)2011 


\begin{abstract}
Heterotaxy refers to the abnormal arrangement of internal organs in relation to each other. Model organism studies have shown that functions of more than eighty genes are required for normal asymmetric left-right organ development. CRELD1 has been shown to be necessary for proper heart development and mutations in CRELD1 are known to increase risk of cardiac atrioventricular septal defects (AVSD). AVSD is the most common form of heart defect associated with heterotaxy, and we have previously shown that some individuals with heterotaxy-related AVSD have mutations in CRELD1.

Therefore, we propose to examine the CRELD1 gene in a large sample of patients with heterotaxy syndrome. Our goal was to determine if mutations in CRELD1 are associated with other manifestations of heterotaxy or if they only coincide with AVSD. To achieve this aim, a sample size of 126 patients with heterotaxy collected by Dr. Belmont, Baylor college of Medicine, Texas, with approximately $66 \%$ of the heterotaxy population with different types of heart defects, were used for this study. Ten exons, promoter regions, and regulatory elements in the introns of CRELD1 gene were sequenced and analyzed.

In this study three different heterozygous missense mutations in CRELDI were identified in three unrelated individuals. These three individuals were diagnosed with different forms of heart defects in addition to AVSD. All three mutations were identified in highly conserved regions of CRELD1 possibly altering the CRELD1 properties. This demonstrates that mutations in CRELD1 may increase the
\end{abstract}


susceptibility of AVSD in heterotaxy population. This information can help us to find factors effecting disease susceptibility in heterotaxy patients since the heart defects are a complex trait with incomplete penetrance. 


\section{Dedication}

This thesis is dedicated to my dear parents, who offered their unconditional love and support throughout this adventure and always encourage me to go through challenges. 


\section{Acknowledgements}

First and foremost I would like to thank my thesis committee for their expertise and guidance: Dr. Deborah Duffield, Dr. Cheryl Maslen, and Dr. Suzanne Estes. I am eternally grateful and appreciate the support from Maslen lab members, Dr. Jennifer Redig, Darcie Babcock, and Ben Reshey. I would also like to thank Dr. John Belmont from Baylor College of Medicine for providing the samples for this study and Dr. Subrata Dey for collaboration. Funding for this project was granted by NIH R01083300, ULI RR024140, and Oregon Clinical Translational Research Institute. Finally, I thank my loving family, Sophia Trieu, Yun Xin Lim and other dear friends who embraced this project with me. 


\section{TABLE OF CONTENTS}

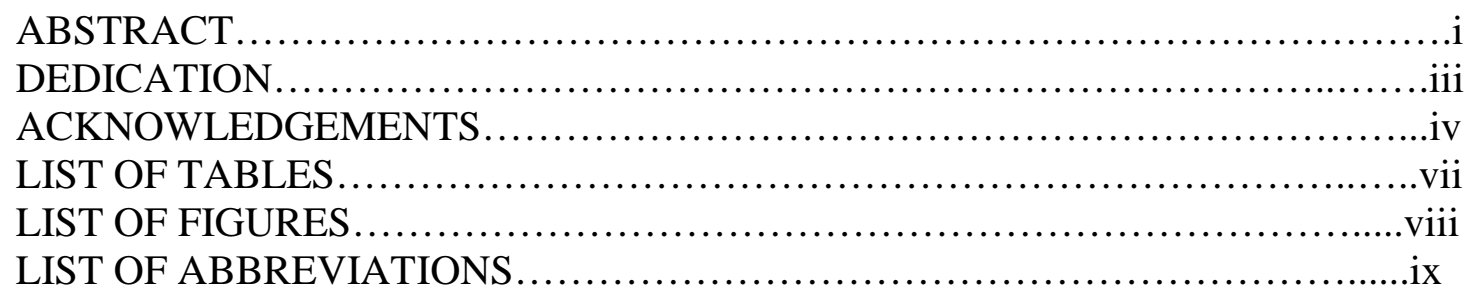

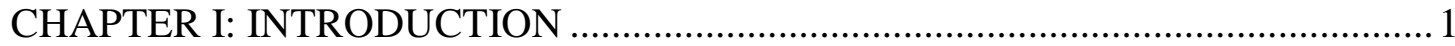

1.1-HETEROTAXY AND PHENOTYPIC CHARECTRISTICS ...................... 1

1.2-EPIDEMIOLOGY AND INHERITANCE OF HETEROTAXY AND OTHER DISORDERS OF L-R ASYMMETRY ………….............................. 3

1.3-L-R AXIS ESTABLISHMENT DURING EMBRYONIC

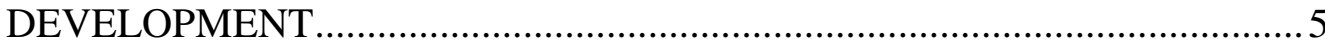

1.4-CLINICAL AND PRENATAL EVALUATION OF HETEROTAXY ........9

1.4.1-THE CLINICAL EVALUATION OF HETEROTAXY ................9

1.4.2-PRENATAL EVALUATION ………………………………..... 11

1.5-GENETIC RISK FACTORS AND MOLECUALR DIAGNOSTICS ........12

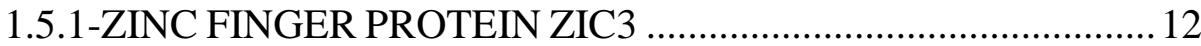

1.5.2-NODAL, LEFTYA, CRYPTIC, AND ACVR2B ………............... 14

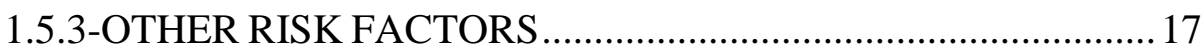

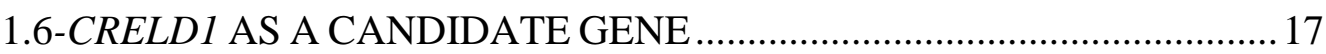

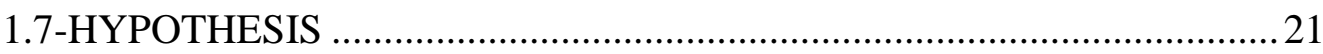

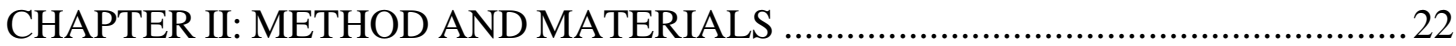

2.1-CLINICAL EVALUATION AND SAMPLING........................................22

2.2-DESIGN OF OLIGONUCLEOTIDE PRIMERS ......................................... 22

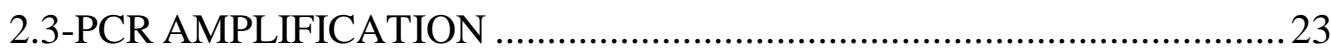

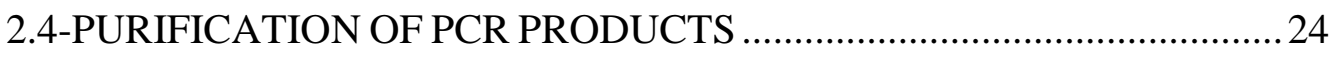

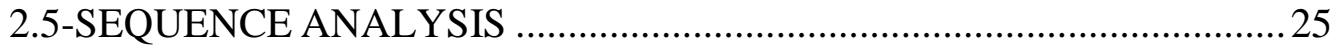

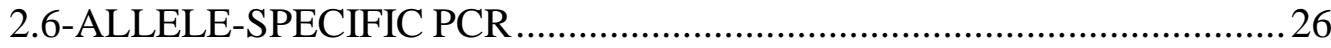

2.7-POLYMORPHISM PHENOTYPING (POLYPHEN-2).............................27 


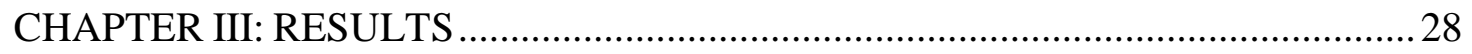

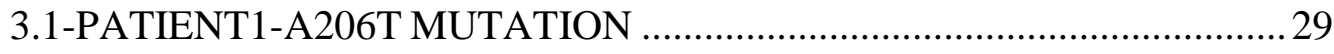

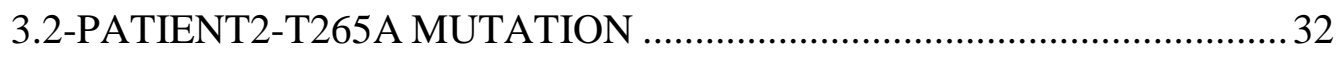

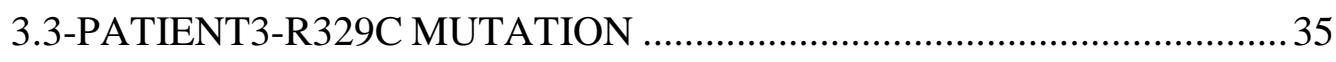

3.4-OTHER SIGNIFICANT VARIANTS IN CRELD1 …………………........ 36

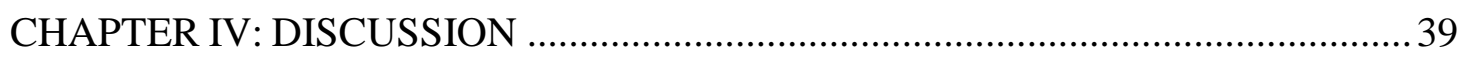

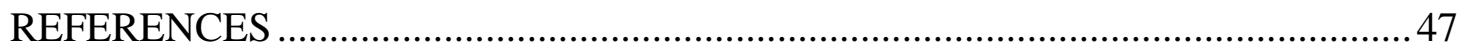

APPENDIX: CRELDI GENOMIC SEQUENCE..................................................... 


\section{LIST OF TABLES}

Table 1.1: Congenital anomalies associated with heterotaxy ................................ 2

Table 2.1: Oligonucleotide primers for CRELD1 exon amplication by PCR ............. 24

Table 2.2: Template quantities for 1 Xcycle-sequencing run .....................................25

Table 2.3: Oligonucleotide primers for CRELD1 exon sequencing ...........................25

Table 2.4: ASP primer sequence ................................................................. 26

Table 3.1: The frequency of different abnormalities found in heterotaxy population of

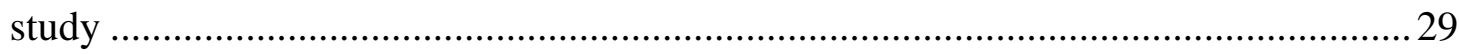

Table 3.2: Non-synonymous variants in CRELD1 found in heterotaxy patients ......... 38 


\section{LIST OF FIGURES}

Figure 1.1: Overview of L-R asymmetry in mouse embryo 6

Figure 1.2: Mice embryo at the developmental stage .................................................20

Figure 3.1: CRELD1 protein and the relative position of amino acids ......................... 30

Figure 3.2: Sequence analysis identifying first missense mutation in CRELD1.......... 31

Figure 3.3: Diagrammatic representation of CRELD1 protein ......................................32

Figure 3.4: Illustration of different heart defects.......................................................... 33

Figure 3.5: Sequence analysis identifying second missense mutations in CRELD1 ....34

Figure 3.6: Sequence analysis identifying third missense mutations in CRELD1 ........36

Figure 4.1: Approximate ratio of heterotaxy patients diganosed with heart defects and

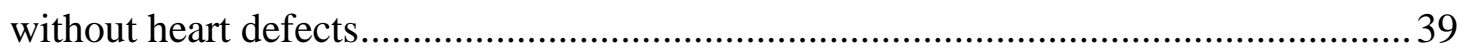

Figure 4.2: Alanine and threonine chemical structure.................................................. 41

Figure 4.3: Arginine and cysteine chemical structure ………………..........................4

Figure 4.4: Diagrammatic representation of the two cb-EGF domain of CRELD.......45 


\section{LIST OF ABBREVIATIONS}

A-P: Anterior-posterior

ALK: Activin-like receptors

ASD: Atrial septal defects

ASP: Allele specific PCR

AVSD: Atrioventricular septal defects

BBS: Bardet-Biedl syndrome

CHD: Congenital heart defects

CoA: Coarctation of the aorta

CRELD: Cysteine rich with EGF like domains

D-V: Dorsal-ventral

DILV: Double inlet left ventricle

DMSO: Dimethyl sulfate

dNTP: Deoxynucleotide triphosphate

EGF: Epidermal growth factor

FGF: fibroblast growth factor

L-R: Left-right

LPM: Lateral plate mesoderm

MGA: Malposition of great arteries

PCD: Primary ciliary dyskinesia

PCR: Polymerase chain reaction

SNP: Single nucleotide polymorphism 
TGA: Transposition of great artery

TGF: Transcription growth factor

cb-EGF: Calcium binding-EGF

VCFS: Velo-Cardio-Facial syndrome

VSD: Ventral septal defects

ZFDs: Zinc finger domains 


\section{CHAPTER I: INTRODUCTION}

\section{1-HETEROTAXY AND PHENOTYPIC CHARACTERISTICS}

Heterotaxy (hetero meaning 'other' and taxy meaning 'arrangement') refers to an abnormal developmental condition characterized by randomized arrangement of the thoracic and/or abdominal visceral organs, including the heart, lungs, liver, stomach, and spleen. The organs are either located randomly with respect to the leftright (L-R) axis or to one another. This genetic disorder is characterized by multiple congenital malformations and complex cardiovascular malformation that is reported to be the major cause of morbidity and mortality in this population (Table1.1).

Heterotaxy accounts for approximately $3 \%$ of all congenital heart defects (CHD) with an approximate prevalence of 1:10,000 live births (Lin et al., 2000), most frequently diagnosed in the newborn mainly due to cyanotic congenital heart disease (Sutherland and Ware, 2009). In individuals with heterotaxy any internal organ that is asymmetrically positioned can be abnormal and the midline defect, which results from disclosure of neural tube, occurs in approximately $40 \%$ of patients (Zhu et al., 2006). The wide phenotypic spectrum seen in heterotaxy, in combination with the lack of formal clinical guidelines for the evaluation, has made the identification of patterns of laterality defects more complicated. Thus these patients require an extensive diagnostic evaluation and multiple imaging studies in order to define their anatomy as well as chromosome microarray analysis due to associations with chromosome abnormalities. 
Table 1.1: Congenital anomalies associated with heterotaxy (Zhu et al., 2006)

Cardiovascular

Gastrointestinal

Pulmonary

Central nervous system

Genitourinary/anal

Musculoskeletal

Immune

Ear, Nose, and Throat
Atrioventricular discordance Atrial isomerism

Double outlet right ventricle

Pulmonary stenosis or atresia

Transposition of the great arteries

Single ventricle

Left ventricular outflow tract

obstruction

Septal defects

Total/partial anomalous venous

return

Interrupted inferior vena cava

Bilateral superior vena cava

Conduction system abnormalities

Extrahepatic biliary atresia

Intestinal malrotation

Omphalocoele

Duodenal atresia/obstruction

Tracheoesophageal fistula

Annular pancreas

Microgastria

Midline liver

Right-sided stomach

Hyparterial or eparterial bronchi Impaired mucociliary clearance in patients with ciliary defect

Neural tube defect

Imperforate anus

Sacral dysplasia

Renal dysplasia

Horseshoe kidney

Fused adrenal glands

Bifid or septate uterus and vagina

Vertebral and rib anomalie

Asplenia or polyspleni

Cleft palate 


\section{2-EPIDEMIOLOGY AND INHERITANCE OF HETEROTAXY AND OTHER DISORDERS OF L- R ASYMMETRY}

Situs inversus, referring to complete mirror image arrangement of all internal organs, is estimated to occur in 1 in 8,000-25,000 individuals and is mainly due to abnormal cilia function or absent of cilia lining the respiratory tract known as primary ciliary dyskinesia (PCD). PCD is also associated with a wide variety of human diseases such as bronchitis, infertility, hydrocephalus, anosmia, and retinitis pigmentosa (Afzelius et al., 2001; Pan et al., 2005), and has an autosomal recessive inheritance pattern.

Situs ambiguous, which refers to abnormal arrangement of internal organs with discordance of thoracic and visceral anatomy is mainly characterized by congenital anomalies and is estimated to take place in 1:10,000 live births (Lin et al., 2000). Most cases of situs ambiguous occur sporadically and do not follow obvious Mendelian inheritance patterns, although phenotypic characterization of families suggests both autosomal recessive and dominant patterns with incomplete penetrance due to evidence of familial clustering. Family studies have identified isolated cardiac defects, isolated neural tube defects, or abnormal vasculature in unaffected individuals (Morelli et al., 2001).

Laterality defects, which refer to any deviation from situs solitus including the failure to generate asymmetry, can arise in a single individual (Kosaki and Casey, 1998; Winer-Muram, 1995) but are especially associated with monozygotic twinning. Environmental factors such as exposure to drugs or chemicals such as 
nitrous oxide, retinoic acid, phenylephrine, methoxamine, have been reported to associate with L-R phenotypes in animal models (Levin, 2005).

Isolated dextrocardia, which refers to right-sided heart position, showed a strong association with a family history of CHD and extracardiac anomalies. A population based study of cardiovascular malformation indicated that maternal diabetes and first trimester cocaine use are associated with heterotaxy (Kuehl and Loffredo, 2002).

Heterotaxy most often occurs as a sporadic condition. Genetic mechanisms underlying heterotaxy are still not completely known, but the familial studies have suggested a complex inheritance or autosomal dominant and autosomal recessive inheritance with reduced penetrance and variable expressivity. (Vitale et al., 2001; Belmont et al., 2004; Zhu et al., 2006; Wessels et al., 2008).

$\mathrm{X}$-linked inheritance is well documented in heterotaxy and is caused by mutations in ZIC3 (Gebbia et al., 1997). A large number of genetic syndromes and chromosome abnormalities have been associated with heterotaxy, including aneuploidies, complex chromosomal rearrangements, and microdeletions (Bisgrove et al., 2003; Ware and Belmont, 2008; Song et al., 2009). Reported examples are patients with trisomy 13 or trisomy 18 . In addition, a number of submicroscopic chromosomal deletions, including 22q11.2 DiGeorge/Velocardiofacial Syndrome (VCFS) syndrome, have been identified in patients with heterotaxy. Bisgrove et al. (2003) reviewed unbalanced translocations, terminal deletions, inversions, and more complex chromosomal rearrangements associated with heterotaxy. 
Analysis of genes located within submicroscopic chromosomal imbalances in patients with abnormal L-R asymmetry should be a useful tool in uncovering novel genetic pathways in laterality defects. However, it is not yet clear what percentage of isolated cardiac defects are mechanistically related to early L-R patterning abnormalities. In addition, the true incidence of human L-R patterning defects is not yet known and so further definition of the molecular basis may identify a higher incidence that has been recorded and a better understanding of this genetic disorder.

\section{3-L-R AXIS ESTABLISHMENT DURING EMBRYONIC DEVELOPMENT}

The congenital disorder in patients with heterotaxy mainly results from failure to establish normal L-R asymmetry during embryonic development, with major morbidity and mortality resulting from complex cardiovascular malformations (Sutherland and Ware, 2009). The L-R asymmetry of the heart is closely connected to its function and alteration in cardiac situs represent a significant source of human heart malformations (Kathiriya and Srivastava, 2000). Since the L-R axis is established during early development, a basic understanding of an embryonic tissues and molecular events involved in $\mathrm{L}-\mathrm{R}$ axis formation is beneficial for initiating a diagnostic work-up, understanding the genetic basis of disease, and assessing recurrence risk.

The L-R axis is established early in embryogenesis subsequent to the development of anterior-posterior (A-P) and dorsal-ventral (D-V) axes. Recent work 
with model organisms has offered a detailed view of the steps taken to establish asymmetry in the vertebrate (Bisgrove and Yost, 2001). In Fig.1.1, five steps in developing L-R asymmetry in the mouse embryo are illustrated. The early stage of L-R patterning occurs before cilia are established at the node, a transient embryonic organizer. This involves processes such as planar cell polarity in which asymmetric gradients are established within a cell, across a sheet of cells and ultimately throughout the embryo (Aw and Levin, 2009). The signaling pathways and the molecular mechanisms of early stage of L-R patterning during embryogenesis are not yet well defined and may vary by model organism (Sutherland and Ware, 2009).

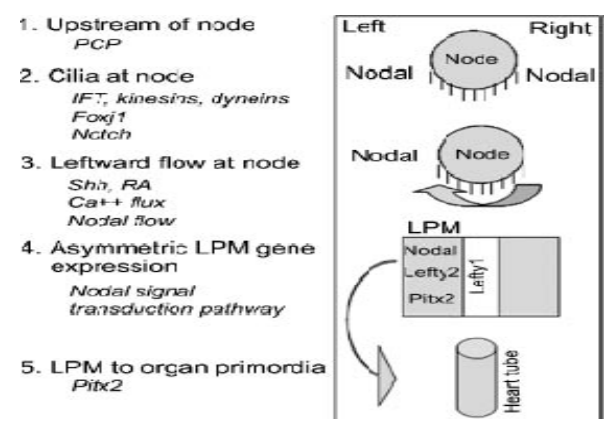

Figure 1.1: Overview of L-R asymmetry in mouse embryo (Sutherland and Ware, 2009). Evidence shows intercellular asymmetry involving mechanism such as Planar cell polarity (PCP) take place before the establishment of the node or cilia. During the second stage, the node and functioning motile cilia form. Centrally located monocilia are motile and peripheral monocilia lack $\mathrm{L}-\mathrm{R}$ dynein and are immotile. In the next stage, the movement of cilia at the node creates a leftward flow of morphogens. Nodal expression is initially bilateral, but becomes asymmetrically expressed on the left, providing molecular evidence of L-R asymmetry. During the stage four, Nodal signal is propagated from the node to the lateral plate mesoderm (LPM) where asymmetric gene expression is established. In stage five, asymmetric signaling is propagated from the LPM to organ primordia in order for proper morphogenesis to occur. 
During the second stage of mouse embryo development, the node and functioning motile and sensory cilia form. The genetic control of node morphogenesis is unknown but it has been proven that Notch signaling, which allows a cell-cell communication, is necessary for both proper node structure as well as later asymmetric nodal expression (Krebs et al., 2003; Przemeck et al., 2003; Takeuchi et al., 2007). In addition, at this stage the monocilia located at center are motile compare to immotile peripheral monocilia (McGrath et al., 2003). This characteristic allows the movement of cilia at the node, creating a leftward flow of morphogens, which form the clockwise rotational motion of the cilia and creating a unidirectional flow in stage 3, which is essential for proper L-R asymmetry (Sutherland and Ware, 2009).

In the next stage, as results of leftward flow of cilia, fibroblast growth factor (FGF) signaling triggers the releases of particles carrying the morphogens Sonic hedgehog and retinoic acid, which are pushed to the left of the node and trigger a cascade of gene expression (Okada et al., 2005; Hirokawa et al., 2006). In addition, the unidirectional flow of extracellular fluid bends the peripheral immotile cilia surrounding the node, resulting in an asymmetric cytoplasmic calcium flux (McGrath et al., 2003). These two pathways effect Nodal expression which initially is bilateral, but becomes asymmetrically expressed on the left, providing the first molecular evidence of L-R asymmetry which is critical for subsequent left-sided gene expression in the lateral plate mesoderm (LPM) (Sutherland and Ware, 2009). 
In stage four, Nodal signal transduction pathway expressed in the left side of the node and the signal is propagated to the LPM where asymmetric gene expression is established. At the presence of an EGF-CFC cofactor, Nodal signals through type I and type II receptors and activates two antagonists Lefty-1 (LEFTYA in human) and Lefty-2 (LEFTYB in human) which are expressed in the midline and in the LPM, respectively. This activation limits Nodal expression and subsequently inhibits the transfer of left-sided gene expression across the midline of the embryo. Pitx2, a homeobox transcription factor, is also activated by Nodal and is asymmetrically expressed in the LPM as well as in various organs. This molecular asymmetry is much conserved across vertebrates and the majority of the known human heterotaxy mutations have been discovered in this pathway. However, mutations within this pathway cause heterotaxy in a minority of cases, indicating that novel genetic etiologies remain to be determined (Sutherland and Ware, 2009).

In the final stage, asymmetric signaling is propagated from the LPM to organ primordia in order for proper morphogenesis to occur. The asymmetric Pitx2 expression persists after the disappearance of the Nodal signal, and involves in organogenesis in the heart, gut, and lungs, demonstrating asymmetric expression in developing organ primordia. Information about cardiac specific targets during looping morphogenesis is currently lacking and needs further investigation.

Study of L-R asymmetry using model organism has shown that heterotaxy may result from defects in any of these five steps. Isolated dextrocardia or CHD related to abnormal laterality can also result from abnormalities at various stages of 
L-R patterning. However, a detailed genetic mechanism of the pathway is still remains to be determined.

\section{4-CLINICAL AND PRENATAL EVALUATION OF HETEROTAXY}

\subsection{1-The clinical evaluation of heterotaxy}

Although heterotaxy shows broad phenotypic variability, the approach to studying this population is relatively straightforward. The first and most important step during clinical evaluation of laterality defects is to identify the full phenotypic spectrum of abnormalities in the proband and to determine whether it is a case of situs inversus or situs ambiguous. This information is essential for patient management as well as providing information that is critical for identification of the possible underlying genetic etiology.

Patients with situs inversus should have evaluation of ciliary function. In addition the signs of Bardet-Biedl syndrome (BBS), including obesity, retinitis pigmentosa, and mental retardation, should be evaluated. Although situs inversus is infrequently reported in BBS, it occurs at a significantly higher rate than in the general population (Ansley et al., 2003). Mutations in BBS2 and BBS8 have been reported in association with situs inversus. Five out of eight known $B B S$ genes encode basal body or cilia proteins, implying a potential for laterality defects (Beales, 2005). Infantile nephronophthisis is another genetic disorder that is associated with situs inversus. This is an autosomal recessive cystic kidney disease which is caused by mutations in INVERSIN (Otto et al., 2003). Lacking evidence of 
cystic kidneys or stigmata of BBS, a patient with situs inversus is classified as having PCD, previously known as immotile cilia syndrome, and therefore and should be followed by a pulmonologist or allergist/immunologist as needed (Zhu et al., 2006).

Patients with situs ambiguous require an extensive diagnostic evaluation directed toward defining the anatomy and preventing potential complications. The evaluations tailored based on data collected from performing an echocardiogram and/or cardiac MRI, abdominal and renal ultrasound, and vertebral X-rays. In addition, the spleen should be evaluated by ultrasound and a peripheral blood smear to detect the presence or absence of Howell-Jolly bodies, red blood cell inclusions indicating abnormal spleen function.

A three-generation pedigree is an essential component of the evaluation. For situs ambiguous, any family history of congenital anomaly is potentially contributory. In addition, mouse models suggest that increased pregnancy loss may be associated with mutations in genes responsible for L-R patterning (Zhu et al., 2006). In addition, there are large numbers of other syndromes that are associated with laterality defects that can be used for clinical evaluation (Aylsworth, 2001). Among aneuploidies, both trisomy 13 and trisomy 18 can cause congenital anomalies overlapping situs ambiguous that can potentially complicate prenatal counseling if amniocentesis is not performed (Ware and Belmont, 2004). Microdeletion 22q11.2 can be detected by karyotype which is associated with laterality defects (Aylsworth, 2001). It is likely that a number of complex malformation syndromes result from early developmental patterning defects in which laterality can be disrupted. 


\subsection{2-Prenatal evaluation}

The frequency of identified heterotaxy cases on prenatal ultrasound has increased as the result of advances in imaging technology (Berg et al., 2003). For example, fetal echocardiography has provided a tool for detailed study of the structure of an unborn baby's heart. Early fetal heart block is commonly associated with left isomerism and early detection of the disorder is critical for clinical management (Jaeggi et al., 2005). In the absence of a syndromic diagnosis, the prognosis of the fetus is largely based on the cardiac anatomy and/or the presence of biliary atresia. Biliary atresia is a disorder of infants in which there is progressive obliteration or discontinuity of the extrahepatic biliary system, resulting in obstruction of bile flow, requiring liver transplantation within the first year of life (Leyva-Vega et al., 2010). Biliary cystic malformations can be identified prenatally and, although not specific for biliary atresia, are highly suspicious when identified in conjunction with other laterality defects. Since the inheritance patterns of heterotaxy is very complicated and varies among individuals, genetic counseling in prenatal cases is complex. In addition to discussion of the anatomic defects and their prognosis and management, counseling sessions should also include discussion of both syndromic and nonsyndromic possibilities and an explanation of inheritance patterns. However, to gain a better understanding of these disorders, analysis of genes involve in L-R asymmetry would be a powerful tool in uncovering novel genes and pathways in laterality defects. 


\section{5-GENETIC RISK FACTORS AND MOLECULAR DIAGNOSTICS}

Model organism studies have shown that functions of more than eighty genes are required for normal asymmetric L-R organ development. While some of these genes probably have a conserved function in humans and any mutation in them are lethal, mutations in relatively few genes have been identified in patients with heterotaxy. These include ZIC3, LEFTYA, CRYPTIC and ACVR2B, and single cases of mutations in NKX2.5 and CRELD1 have been reported in patients with dextrocardia (Watanabe et al., 2002; Robinson et al., 2003). The contribution of mutations in these genes to heterotaxy or L-R patterning defects in the heart remains to be characterized further in larger sample sets (Zhu et al., 2006). In all these mutation studies, conventional methods of assessing the role of particular rare variants as mutations have been used. This usually includes analysis of controls for the particular variant. However, there is very little power to repeatedly detect rare variants, even in very large control sets.

\subsection{1-Zinc finger protein ZIC3}

The zinc finger domains (ZFDs) of the Zinc family proteins have been strongly conserved over the evolution of a broad range of eumetazoan animals (Aruga et al., 2006) suggests they provide the structural basis for the essential roles of Zic family protein in animal development (Aruga, 2004; Herman and El-Hodiri, 2002). In humans there are five members of the ZIC family that are involved in 
congenital anomalies (Grinberg and Millen, 2005). One of them, ZIC3, was the first gene identified to have a casual role in defects in human laterality (Ferrero et al., 1997; Gebbia et al., 1997). Mutations in ZIC3, which is on the X chromosome, can cause the X-linked form of heterotaxy, HTX-1 (OMIM\#306955).

ZIC3 was first identified as a gene preferentially expressed in mouse cerebellum (Aruga et al., 1996) and has the ability to bind DNA and activate transcription (Mizugishi et al., 2001). Zic3-deficient mice develop a broad range of abnormalities in addition to heterotaxy such as neural tube defects, skeletal patterning defects, cerebellar hypoplasia and abnormal behavior (Carrel et al., 2000; Klootwijk et al.,2000; Purandare et al., 2002; Aruga et al., 2004).

ZIC3 protein is made of five tandemly repeated $\mathrm{C} 2 \mathrm{H} 2$ zinc finger transcription factors that are involved in early patterning of the vertebrate embryo. In human, missense mutations that result in changes in cysteine 253 (C253S) or histidine $286(\mathrm{H} 286 \mathrm{R})$ are found in heterotaxy patients and cause extracellular localization of the mutant ZIC3 protein (Ware et al., 2004). Another mutation that alters a tryptophan residue $(\mathrm{W} 255 \mathrm{G})$ is associated with transposition of the great artery (TGA), a CHD that might be an expression of a L-R laterality disturbance (Chhin et al., 2007). Loss of function of this gene has also been reported to associate with other abnormalities such as double outlet right ventricle, and ventricular inversion (Sutherland and Ware, 2009).

Approximately $1 \%$ of sporadic heterotaxy cases (male and female) are caused by mutation in ZIC3. In addition, affected females have been described with point 
mutations or with chromosomal translocations at this gene(Megarbane et al., 2000; Ware et al., 2004; Fritz et al., 2005; Tzschach et al., 2006; Chhin et al.,2007). Carrier females who are heterozygous for ZIC3 mutation are clinically unaffected although a subset has situs inversus (Casey et al., 1993; Gebbia et al., 1997). Deletion of the ZIC3 locus has been associated with situs ambiguous, suggesting the cause of pathogenesis in the patients with the point mutations (Ferrero et al., 1997).

These findings have suggested that isolated CHD may be caused by genes involved in L-R axis development and that there may be variable expression of mutant alleles within and between families. It is currently unclear to what degree ZIC3 mutations contribute to sporadic heterotaxy, and this information is necessary to provide accurate counseling information to families. Mice models suggest that ZIC3 acts upstream of Nodal signaling at the node, however its detailed developmental function is not yet clear (Purandare et al., 2002; Ware et al., 2006).

\subsection{2-NODAL, LEFTYA, CRYPTIC, and ACVR2B}

NODAL is a member of the transcription growth faction (TGF)- $\beta$ family and is involved in cell differentiation. The pattern of $N O D A L$ expression and its developmental function has largely conserved among vertebrates. In the mouse, it is known to have an essential role in early embryonic development including mesoderm and endoderm formation and L-R axis patterning. During gastrulation stage of development, $N O D A L$ is expressed in the epiblast and visceral endoderm, and it 
induces its co-receptor Cripto, which controls A-P patterning. Lack of NODAL expression in mice causes the absence of primitive streak and loss of mesoderm formation (Conlon et al., 1994; Lowe et al., 1996; Zhou et al., 1993). The functions of NODAL have been examined in other species, and in all of them NODAL orthologs are expressed asymmetrically in the left side of the node as well as in left lateral plate mesoderm (Schier and Shen, 2000; Whitman, 2001). This data shows that the Nodal signaling cascade within the lateral plate mesoderm is required for LR patterning in vertebrates (Mercola and Levin, 2001; Hamada et al., 2002; Schier, 2003), and any disturbance in expression of $N O D A L$ can lead to polarity reversal of visceral organs and heart looping (Harvery, 1998). Mutations in NODAL have been identified in patients with heterotaxy following an autosomal dominant inheritance pattern (Kosaki et al., 1999; Bamford et al., 2000; Goldmuntz et al., 2002; Selamet Tierney et al., 2007; Roessler et al., 2008; Mohapatra et al., 2009).

Nodal signaling uses an Activin/TGF- $\beta$-like pathway mediated by several Activin-like receptors (ALKs). NODAL signals via ALK4 and AKL7 in association with either ActRIIA or ActRIIB (Whitman 2001). The activated receptor complex phosphorylates an intracellular receptor-regulator known as Smads. This phosphorylated complex binds to Smad4 and that results in its translocation to the nucleus (Attisano and Wrana, 2002). This complex then can either bind DNA directly or can interact with other DNA binding proteins such as transcription coactivator FoxH1 to regulate the promoters of various genes. In addition, FoxH1 regulates Nodal signaling pathway by binding to the NODAL and Lefty 2 asymmetric 
enhancer element (Saijoh et al., 2000). Mutations in several components of the Nodal signaling pathway in animal models has exhibit defects in L-R axis development (Pogoda et al., 2000; Yamamoto et al., 2001; Yan et al., 2002). Mutation in components of the Nodal signaling pathway, such as genes encoding the ligand (NODAL), ligand co-receptor (CFC-1), receptor (ACVRIIB), FOXH1, and midline inhibitor (LEFTYA) within the Nodal signal transduction pathway, have been identified in human heterotaxy (Kosaki et al., 1998; Bamford et al., 2000; Goldmuntz et al., 2002; Selamet Tierney et al., 2007; Roessler et al., 2008; Mohapatra et al., 2009). Biochemical studies indicate that Cripto (TDGF1) and Cryptic (CFC1) in mouse and human form complexes with NODAL, ALK4/ALK7 and ActRIIB and act as a co-receptor for NODAL at the cell surface (Bianco et al., 2002; Yan et al., 2000).

Study on NODAL variants in 269 patients with heterotaxy or isolated cardiovascular observed missense mutations in 14 unrelated patients (Mohapatra et al., 2009). Functional analysis of the mutant proteins showed a decrease in Nodal signaling. Similarly, functional analysis of mutations in Cryptic ( $C F C 1)$, a gene encoding an epidermal growth factor family protein, CFC1, which functions as a NODAL co-receptor, revealed abnormal cellular localization of the mutant protein (Bamford et al., 2000). ACVRIIB mutations were identified in 3 of 126 patients with left-right anomalies and mutations in LEFTYA were discovered in 2 patients (Kosaki et al.,1998). The study showed that each patient inherited the mutant allele from an 
unaffected carrier parent, indicating autosomal recessive inheritance pattern or incomplete penetrance.

\subsection{3-Other risk factors}

With over hundred candidate genes identified through mouse models of $\mathrm{L}-\mathrm{R}$ patterning defects, it is likely that significant genetic heterogeneity will be found in human heterotaxy. To date, the majority of genes identified have either not yet been tested in larger heterotaxy populations or have been found to have mutations at a low frequency (Watanabe et al., 2002; Robinson et al., 2003). For example, positional cloning of a region involved in a reciprocal translocation in one patient identified SESN1, a gene involved in L-R patterning. Functional analysis of this protein revealed that it plays a role in activating Nodal signaling. However, the prevalence of disease causing mutations in this gene is less than $1 \%$ based on an initial screen of a heterotaxy cohort (Peeters et al., 2003, Peeters et al., 2006). Efforts are ongoing to identify novel genes that cause or contribute to the heterotaxy phenotype. One of the candidate genes that require a large population study in patients with heterotaxy is CRELD1. Missense mutations in CRELD1 are associated with atrioventricular septal defects (AVSD), including AVSD in patients with heterotaxy (Robinson et al., 2003). 


\section{6-CRELD1 AS A CANDIDATE GENE}

CRELD1 is the member of a highly conserved family of proteins known as CRELD (Cysteine Rich with EGF-Like Domains) (Rupp et al., 2002), that are members of the TGF-superfamily, which contains a diverse array of multifunctional cytokines. This group has one other homologous member, CRELD2. The two members of this family are nearly identical except that CRELD1 is a cell surface molecule, whereas CRELD2 is a secreted protein that is possibly a regulator of CRELD1 function. These cell-surface/extracellular proteins are characterized by tandemly repeated epidermal growth factor-like (EGF) domains and a unique motif called the CRELD domain.

CRELD1 is located on chromosome 3p25 (Rupp et al., 2002) and is the first recognized risk factor for isolated AVSD (Robinson et al., 2003), a common congenital heart malformation affecting the atrioventricular valves and septa that results in a mixing of oxygenated and non-oxygenated blood. In addition, CRELD1 is becoming increasingly recognized as an important factor in cancer biology with numerous proposed biochemical interactions.

CRELD1 missense mutations occur in almost $8 \%$ of individuals with AVSD (Robinson et al., 2003), and 5\% of Down syndrome-associated AVSD cases (Maslen et al., 2006). The highly specific genetic association between CRELDl-missense mutations and AVSD suggests that mutations in CRELD1 significantly increase the risk of developing an AVSD. High level of incidence of AVSD has been reported in heterotaxy patients, presumably due to physical disruption of septation from 
laterality defects. Missense mutations in CRELD1 suggest that defects in CRELD1 may increase the likelihood of AVSD in heterotaxy (Robinson et al., 2003). However, a recent study on a CRELDI knocked out $\left(\right.$ Creld $\left.^{(-/)}\right)$mice model indicates that CRELDI is not associated with laterality defects in mice embryos (Redig et al., submitted).

Fig.1.2 compares Creld $1^{(-/)}$mice embryos with a Creld ${ }^{(+/-)}$and wild type Creld $1^{(++)}$embryos. As can be seen, Creld $1^{(--)}$embryos exhibited underdeveloped organs such as telencephalons and heart. However, the positions of organs is the same in Creld $^{(-/)}$embryos relative to wild-type $C r e l d I^{(+/+)}$with no sign of laterality defects. This indicates that CRELD1 does not cause laterality defects (Redig et al., submitted), but it doesn't rule out the possible role of CRELDI as a risk factor for developing AVSD in a heterotaxy population.

The basic biological function and definition of the CRELD1 biochemical pathway is under investigation. Multiple alternate splice variants of CRELD1 suggest that there are isoforms with diverse functions. CRELD1 can bind to RTN3, an apoptosis-inducing protein responsive to endoplasmic reticulum stress, and controls apoptosis activity of RTN3 (Xiang and Zhao, 2009). In addition, a recent study on cell migration during development suggests the important role of CRELD1 in polarized cell migration (Nystul et al., 2009), a process regulated by Notch signaling which is necessary for proper node structure as well as asymmetrical nodal expression. 
Creld $1^{(++)}$

A
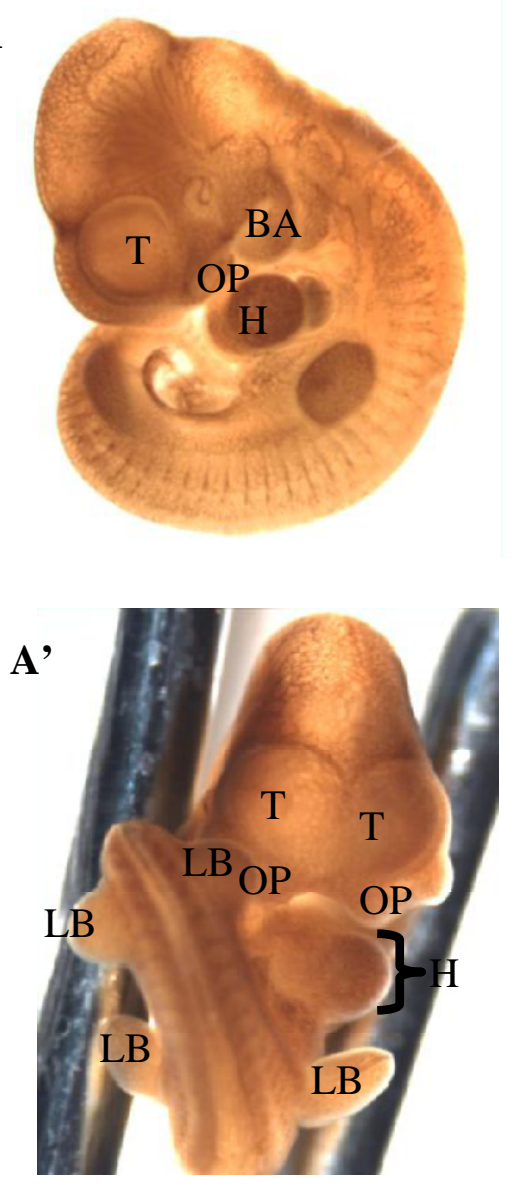

CreldI $^{(+/-)}$

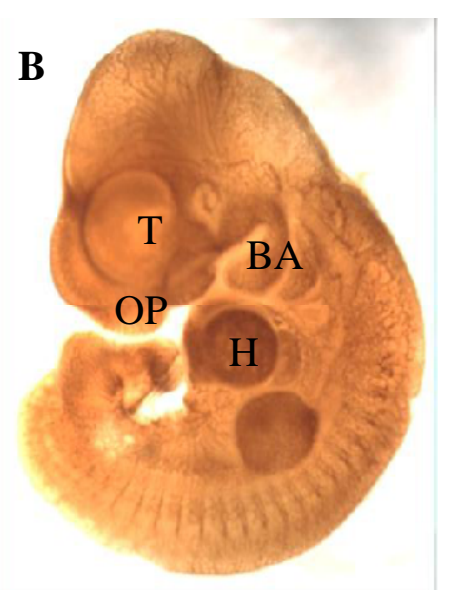

B'

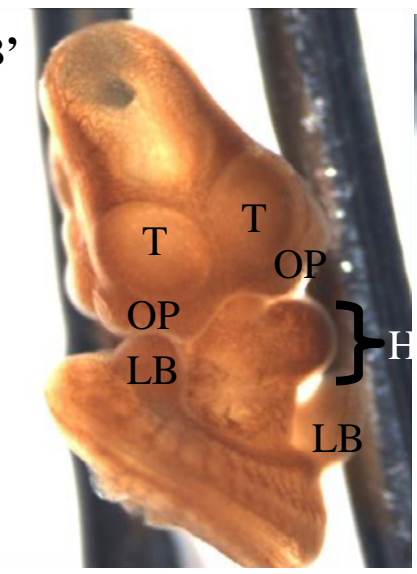

Creld $1^{(-/)}$
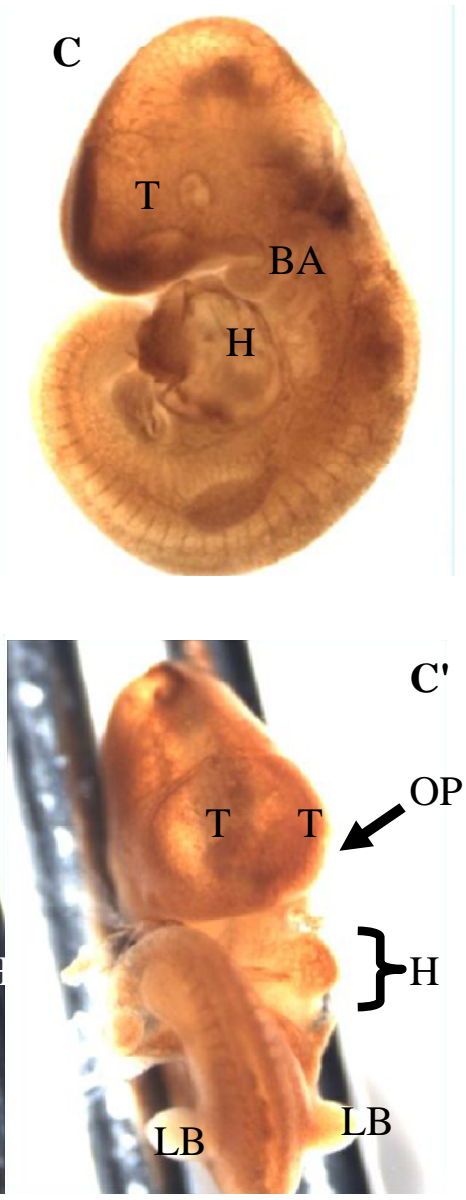

Figure 1.2: Mice embryos at the developmental stage (Redig et al., submitted). The two picture on far left (A,A') are showing the wild-type embryo, two in the middle (B, B') are heterozygous for CreldI $^{(+-)}$and the two other on the far right(C,C') are showing the nocked out mice Creld $^{(--)}$

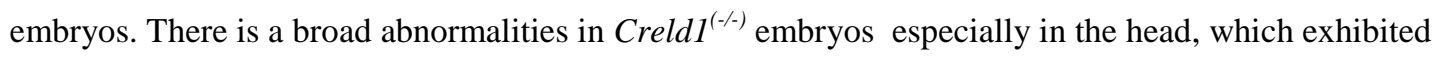
underdeveloped telencephalons, T and underdeveloped olfactory placodes, OP. The position of Limb buds (LB), olfactory placode (OP), branchial arch (BA), telencephalon $(\mathrm{T})$, heart $(\mathrm{H})$ are indicating the absence of laterality defects in Creld $^{(--)}$embryos. 


\section{7-HYРОTHESIS}

Despite all of the indications that CRELD1 plays a role in human early development, no study has been done in large sample of patients with heterotaxy to determine if mutations in CRELDI are a risk factor increasing the likelihood of AVSD in this population. To address this, we examined whether there is a significant difference between the variables in this population. Our hypothesis and alternative hypothesis are:

- Hypothesis: there are missense mutations in CRELD1 which increase the likelihood of AVSD or other CHD in heterotaxy patients.

- Alternative Hypothesis: there is no novel mutation in CRELD1 effecting susceptibility for CHD in this population. 


\section{CHAPTER II: METHOD AND MATERIALS}

\section{1-CLINICAL EVALUATION AND SAMPLING}

The study sample included 126 individuals with a diagnosis of heterotaxy syndrome with or without heart defects, identified by the Baylor College of Medicine, Houston, Texas and provided in collaboration with Dr. John Belmont. The study population ranged broadly in age and sex.

A biological sample for genomic DNA isolation was obtained from each individual, from blood or by buccal samples collected by mouthwash, by the Belmont group using standard technology. The normal control population DNA panels from Caucasian and Hispanic populations were obtained from the Coriell Repository (Camden, NJ).

\section{2-DESigN OF OLIGONUCLEOTIDE PRIMERS}

The coding and known regulatory regions of CRELD1 were screened for point mutations by standard DNA sequencing of PCR amplified genomic DNA. PCR amplification was done using previously designed primers and conditions (Robinson et al., 2003). The primer sequences and amplification profiles are listed in table 2.1. Primers were used to amplify ten exons and two promoter regions as well as at least $50 \mathrm{bp}$ into introns from each junction in a total of seven amplicons. 


\section{3-PCR AMPLIFICATION}

For each patient genomic DNA sample, seven PCR reactions were performed using the primers listed in table 2.1. PCR reactions for regions including exon 3,4,10, and promoter region 2 were performed in a $25 \mu 1$ reaction volume containing $100 \mathrm{ng}$ of genomic DNA, $25 \mathrm{pmol}$ of each primer, and $12.5 \mu \mathrm{l}$ of Invitrogen AccuPrime ${ }^{\mathrm{TM}}$ PCR SuperMixII.

For the rest of the exons and promoter region 1, PCR reactions were performed in a $25 \mu 1$ reaction volume containing $100 \mathrm{ng}$ of genomic DNA, 25 pmol of each primers, $5 \mu \mathrm{l}$ of Herculase II buffer (5x), $2 \mu \mathrm{l}$ of $10 \mathrm{~mm}$ dNTPs, $1.25 \mu \mathrm{l}$ of DMSO, $0.25 \mu \mathrm{l}$ of Herculase II Polymerase (Stratagene; La Jolla, CA, USA). PCR cycling was carried out on a Veriti® Thermal Cycler (Applied biosystems, Ca, USA) using a denaturation cycle at $95^{\circ} \mathrm{C}$ for $2 \mathrm{~min}$, followed by 35 cycles of denaturation at $95^{\circ} \mathrm{C}$ for $15 \mathrm{sec}$ and annealing (Table 2.1) $15 \mathrm{sec}$, and extension step at $72^{\circ} \mathrm{C}$ for 30 sec and a final extension step at $72^{\circ} \mathrm{C}$ for $7 \mathrm{~min}$. The products were visualized by standard ethidium bromide-agarose gel electrophoresis. 
Table 2.1: Oligonucleotide primers for CRELDI amplification by PCR.

\begin{tabular}{|c|c|c|c|}
\hline Amplicon & Primer pair & $\begin{array}{c}\text { Annealing } \\
\text { Temperature } \\
\left({ }^{\circ} \mathrm{C}\right)\end{array}$ & $\begin{array}{l}\text { Product } \\
\text { size } \\
\text { (bp })\end{array}$ \\
\hline $\begin{array}{l}\text { CRELD1 } \\
\text { Promoter } \\
\text { Region } 1\end{array}$ & $\begin{array}{l}\text { Pro 1-F 5' CTG CTT CGA CAG GCT 3' } \\
\text { Pro 1-R 5' ATC CGG ATA TGA AGG 3' }\end{array}$ & 62 & 685 \\
\hline $\begin{array}{l}\text { CRELD1 } \\
\text { Promoter } \\
\text { Region } 2\end{array}$ & $\begin{array}{l}\text { Pro 2-F 5' CGG TCG CTT CTT CCT TCT C } \\
\text { Pro 2-R 5' AGA AGA CTG GGG AGG TGG AG 3, }\end{array}$ & 63 & 665 \\
\hline $\begin{array}{l}\text { CRELD1 } \\
\text { Exons } 1-2\end{array}$ & $\begin{array}{l}\text { E1-F 5', AGC CTC TCC ACG CCC TCT A 3', } \\
\text { E2-R 5' CCT AGC CCT ACA CCA GCA GAG 3, }\end{array}$ & 62 & 600 \\
\hline $\begin{array}{l}\text { CRELD1 } \\
\text { Exons 3-4 }\end{array}$ & $\begin{array}{l}\text { E3-F 5' GAG ACT TGA GGA GGG TGG TG 3' } \\
\text { E4-R 5' AAG CCT TTC CCC ACT GAT TT 3' }\end{array}$ & 58 & 800 \\
\hline $\begin{array}{l}\text { CRELD1 } \\
\text { Exons 5-6 }\end{array}$ & $\begin{array}{l}\text { E5-F 5', TGT ATA GAT GAC CTC ACC TGG TTT 3' } \\
\text { E6-R 5' CTG ACC ATC TTC CCA GAC CT 3' }\end{array}$ & 58 & 400 \\
\hline $\begin{array}{l}\text { CRELD1 } \\
\text { Exons 7-8-9 }\end{array}$ & $\begin{array}{l}\text { E7-F 5' CTC TGG CTT CAG CTT CCC TA 3', } \\
\text { E9-R 5' GCC TGC CTT CTC TTT GAA TG 3' }\end{array}$ & 63 & 800 \\
\hline $\begin{array}{l}\text { CRELD1 } \\
\text { Exon } 10\end{array}$ & $\begin{array}{l}\text { E10-F 5' CCA GGA ACA GGG ATA CGA GTG 3' } \\
\text { E10-R 5' GGT GCT TAC CCC ACT CTC AAA 3' }\end{array}$ & 58 & 400 \\
\hline
\end{tabular}

\section{4-PURIFICATION OF PCR PRODUCTS}

Template quantity was adjusted based on the PCR product size (Table 2.2). 5 $\mu l$ of PCR product was purified using $2 \mu 1$ of ExoSAP-IT® (United States Biochemical, Ohio, USA). The samples were incubated at $37^{\circ} \mathrm{C}$ for $15 \mathrm{~min}$ to degrade remaining primers and nucleotides followed by incubating at $80^{\circ} \mathrm{C}$ for 15 min to inactivate ExoSAP-IT. 
Table 2.2. Template quantities for $1 \mathrm{X}$ cycle-sequencing run

\begin{tabular}{l|l}
\hline Template & Template quantity \\
\hline PCR product: & \\
$100-200 \mathrm{bp}$ & $1-3 \mathrm{ng}$ \\
$200-500 \mathrm{bp}$ & $3-10 \mathrm{ng}$ \\
\hline $\mathbf{5 0 0 - 1 0 0 0} \mathrm{bp}$ & $5-20 \mathrm{ng}$ \\
\hline
\end{tabular}

\section{5-SEQUENCE ANALYSIS}

The templates were sequenced in both directions using the sequencing primers, listed in Table 2.3, by the OHSU General Clinical Research Center DNA Sequencing Facility. The sequencing electropherograms were compared with gene sequences from GenBank accession number NM_001077415.1 using Mutation Surveyor ${ }^{\mathrm{TM}}$ DNA Analysis software (SoftGenetics LLC, Inc).

Table 2.3: Oligonucleotide primers for $C R E L D 1$ exon sequencing

\begin{tabular}{|c|c|}
\hline Region & Primer pair \\
\hline Promoter Region 1 & $\begin{array}{l}\text { Pro 1-F-Seq 5' CTG CTT CGA CAG GCT 3', } \\
\text { Pro 1-R-Seq 5' ATC CGG ATA TGA AGG 3', }\end{array}$ \\
\hline Promoter Region 1 & $\begin{array}{l}\text { Pro 2-F-Seq 5' CGG TCG CTT CTT CCT TCT C } \\
\text { Pro 2-R-Seq 5' AGA AGA CTG GGG AGG TGG AG 3, }\end{array}$ \\
\hline CRELD1 Exons 1-2 & $\begin{array}{l}\text { E1-F-Seq 5' CGC CCT CTA TCT GCA GGT CC 3', } \\
\text { E2-R-Seq 5' GAG CAG AGA TTT GGC GGG GAG GGG A 3' }\end{array}$ \\
\hline CRELD1 Exons 3-4 & $\begin{array}{l}\text { E3-F-Seq 5', GGG TGG TGG GTG GGG TGG GGC 3' } \\
\text { E4-R-Seq 5' CCC ATC TCC CCA GCC CTG TC 3' }\end{array}$ \\
\hline CRELD1 Exons 5-6 & $\begin{array}{l}\text { E5-F-Seq 5' CAC CTG CTT TGG TGT CTT CC 3', } \\
\text { E6-R-Seq 5' TCC CAG ACC TAG CTA GGG CC 3' }\end{array}$ \\
\hline CRELD1 Exons 7-8-9 & $\begin{array}{l}\text { E7-F-Seq 5', TTC AGC TTC CCT ACT AAA TAG GG } 3 \text { ' } \\
\text { E9-R-Seq } 5 \text { ' TCT TTG AAT GAG GAC CTC CC 3' }\end{array}$ \\
\hline CRELDI Exon 10 & E10-F-Seq 5' TAC GAG TGC CAG GCT GCA TC 3' \\
\hline
\end{tabular}




\section{6-ALLELE-SPECIFIC PCR (ASP)}

The Single Nucleotide Polymorphism (SNP) database was queried to identify DNA sequence alterations that were commonly accruing SNPs. In order to detect SNPs for missense amino acid changes found at exon 5, amino acid position A206T, first detected on sequencing data, allele-specific PCR analysis was used on the patient sample and control population.

Genomic DNA was amplified by use of primers that match/mismatch one of the alleles at the 3'-end of the reverse primer (5'-CATACCAGATGGCTGGTG-3' and 5'-CATACCAGATGGCTGGCG-3', mutant and wild type, respectively). The reverse primers were coupled with upstream (forward) primer (5'CTGGTTTGGTGTCTTCCC $-3^{\prime}$ ). Characterization of this assay demonstrated that the wild-type exon 5 primer amplified genomic DNA from both the patient and normal controls, whereas the mutant primer was capable of amplifying only genomic DNA from the affected individual in whom the mutation had been characterized.

Table 2.4: ASP primer sequence.

\begin{tabular}{|c|c|c|}
\hline Name & Primer sequence & PCR condition \\
\hline CRELD1-A206T-200-F & CTG GTT TGG TGT CTT CCC & $95^{\circ} \mathrm{C} \times 2^{\prime}$ \\
\hline CRELD1-A206T-2nd-mut-R & CAT ACC AGA TGG CTG GTG & $\left.\begin{array}{l}95^{\circ} \mathrm{C} \times 15^{\prime \prime} \\
62^{\circ} \mathrm{C} \times 15^{\prime \prime}\end{array}\right\} \times 40$ \\
\hline CRELD1-A206T-2nd-WT-R & CAT ACC AGA TGG CTG GCG & $\begin{array}{l}72^{\circ} \mathrm{C} \times 15^{\prime \prime} \\
72^{\circ} \mathrm{C} \times 7^{\prime}\end{array}$ \\
\hline CRELD1-T265A-2nd-mut-R & CTC ATA GGA GCC CTC AGC & $\begin{array}{l}95^{\circ} \mathrm{C} \times 2^{\prime} \\
95^{\circ} \mathrm{C} \times 15^{\prime \prime}\end{array}$ \\
\hline CRELD1-T265A-2nd-WT-R & CTC ATA GGA GCC CTC AGT & $60^{\circ} \mathrm{C} \times 15^{\prime \prime}$ \\
\hline CRELD1-T265A-200-F & GGT TGG CAA ATG TGG TCT C & $\begin{array}{c}72^{\circ} \mathrm{C} \times 15^{\prime \prime} \\
72^{\circ} \mathrm{C} \times 7^{\prime}\end{array}$ \\
\hline
\end{tabular}


The DNA samples were amplified by PCR using 100 ng of genomic DNA in a $25 \mu 1$ reaction containing $0.2 \mu 1$ of $25 \mathrm{mM}$ of each primer, $5 \mu 1$ of Herculase II buffer (5x), $2 \mu 1$ of $10 \mathrm{~mm}$ dNTPs, $1.25 \mu 1$ of DMSO, $0.25 \mu 1$ of Herculase II Polymerase (Stratagene; La Jolla, CA, USA), and PCR cycling was carried out on a Veriti ${ }^{\circledR}$ Thermal Cycler (Applied biosystems, Ca, USA). Condition for PCR were 2 min of initial activation step at $95^{\circ} \mathrm{C}$ followed by 40 cycles of denaturation at $95^{\circ} \mathrm{C}$ for $15 \mathrm{sec}$ and annealing at $62^{\circ} \mathrm{C}$ for $15 \mathrm{sec}$, and extension at $72{ }^{\circ} \mathrm{C}$ for $30 \mathrm{sec}$ and a final extension step at $72{ }^{\circ} \mathrm{C}$ for $7 \mathrm{~min}$. The products were visualized by standard ethidium bromide-agarose gel electrophoresis. In all cases the primers gave a single band of the expected size, $200 \mathrm{bp}$.

\section{7-Polymorphism Phenotyping (PolyPhen-2)}

PolyPhen-2 (http://genetics.bwh.harvard.edu/pph2) was used to predict possible impact of an amino acid substitution on the structure and function of CRELD1. Polyphen-2 is a bioinformatics tool which uses multiple algorithms to predict the impact of missense mutations on human protein structure. This tool allows the analysis of all human non-synonymous SNPs publicly available via SNP database. 


\section{CHAPTER III: RESULTS}

Out of 126 patients with heterotaxy, approximately $66 \%$ of them were also diagnosed with different type of heart defects (Table 3.1). DNA sequence analysis of CRELD1 in this cohort of 126 study subjects identified three different missense variants (A206T, R329C and T265A) in three unrelated individuals, who had no other mutations or rare variants identified in their genomes. A two base pair GA deletion was found in non-coding sequence of ten other patients in intron position 9959990/1. Four previously characterized common polymorphic variants (rs279552, rs57022843, rs9853613, rs2302786) were also observed in this population but not investigated further. In addition, three other synonymous variants (L304L, P315P and Q368Q) previously seen by our laboratory in other studies were detected (Table 3.2), but were not further characterized as they appeared to have no functional significance. 
Table 3.1: The frequency of different abnormalities found in heterotaxy population of study. Other heart defects were including right sided cardiac apex, mesocardia, hypoplastic left heart syndrome, Left Atrial isomerism, double aortic Arch, L-loop Patent ductus arteriosus, double outlet right ventricle, hypoplastic left ventricle, and interrupted inferior vena cava

\begin{tabular}{l|c}
\hline Abnormality & Number of patients \\
\hline ASD,VSD,AVSD with or without other heart defects & 8 \\
D/L-loop TGA & 8 \\
D/L-loop TGA with CoA & 9 \\
D/L-loop TGA and other heart defects & 4 \\
Situs inversus with or without dextrocardia & 7 \\
Dextrocardia with other heart defects & 38 \\
Heterotaxy only & 4 \\
MGA and other heart defects & 8 \\
Other types of heart defects & \\
\hline
\end{tabular}

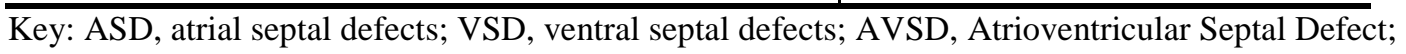

TGA, transposition of great arteris; CoA, coarctation of the aorta; MGA, malposition of great arteries

\section{1-PATIENT1-A206T MUTATION}

Patient 1 was diagnosed with AVSD and dextro-Transposition of the Great Arteries (d-TGA), referred as a complete transposition of the great arteries (Fig.3.4, B). Analysis of the subject's DNA revealed a heterozygous missense mutation. The single-base $\mathrm{G} \rightarrow$ A substitution, at exon position G9957689GA, and cDNA position 615 (c.615G>A), is located in exon 5 and results in a substitution of threonine for 
alanine at amino acid position A206T (Fig.3.2). The amino acid is located in the CRELD domain of CRELD1 (Fig.3.3) with extracellular function. The mutation changes the amino acid located at the sequon position of one of the two N-linked glycosylation sites of CRELD1. Glycosylation is a common post-translational modification for protein molecules involved in cell membrane formation. $\mathrm{N}$-linked glycosylation requires the consensus sequence Asn-X-Ser/Thr which X can be any amino acid but proline. The N-linked glycosylation begins with the addition of a 14sugar precursor to an asparagine amino acid located at the sequon, and it allows the protein to fold correctly followed by further modification in the endoplasmic reticulum (ER) and Golgi. The first N-linked glycosylation site in CRELD1 is located at amino acid position 79 and the second one is at 205 (Fig.3.1). The mutation at this region is possibly affecting the efficiency of glycosylation.

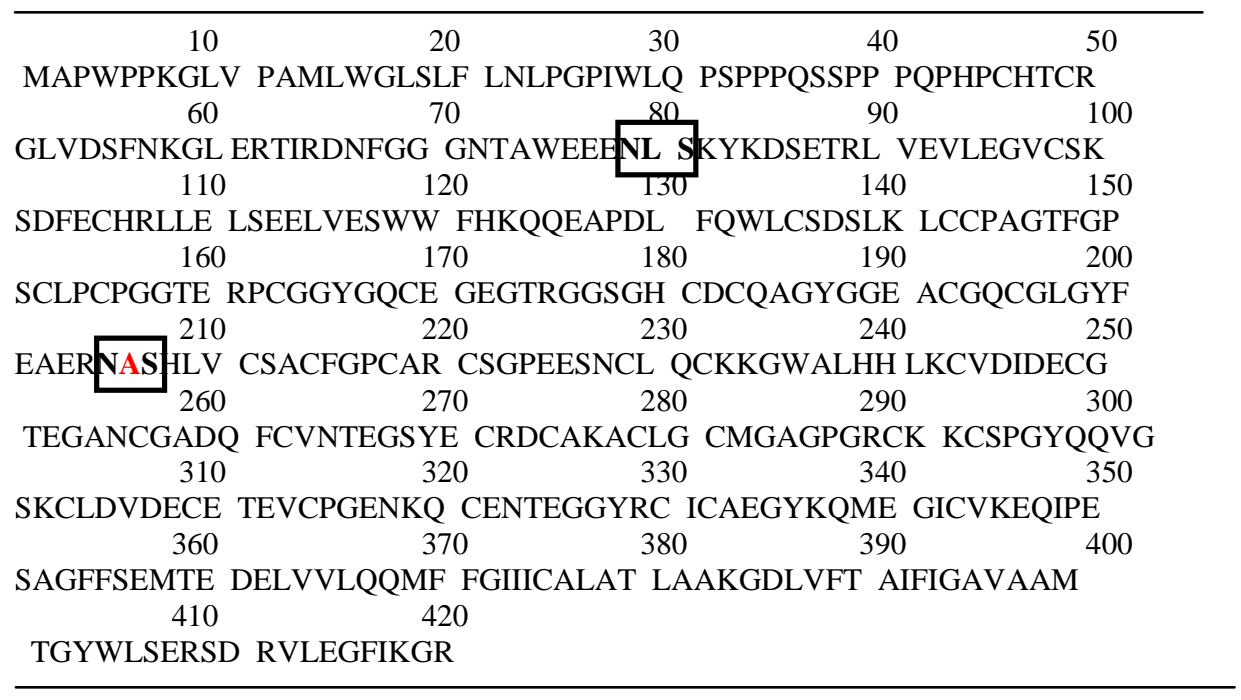

Figure 3.1: CRELD1 protein and the relative position of amino acids. Two N-linked glycosylation sites are shown with the box. The amino acid change is labeled with red color. 
As seen in Fig.3.2 B, the region is conserved within human and bovine but different in mouse. Based on PolyPhen2 analysis this mutation is suggested to have a benign effect on CRELD1 protein structure. The affected subject is of Hispanic descent. The base substitution was not detected in 93 chromosomes from a Hispanic control population indicating that there is $\leq 5 \%$ chance the mutation is a polymorphism in that population with $95 \%$ confidence (Collins and Schwartz 2002) suggesting the variation is unlikely to be a polymorphism.

A

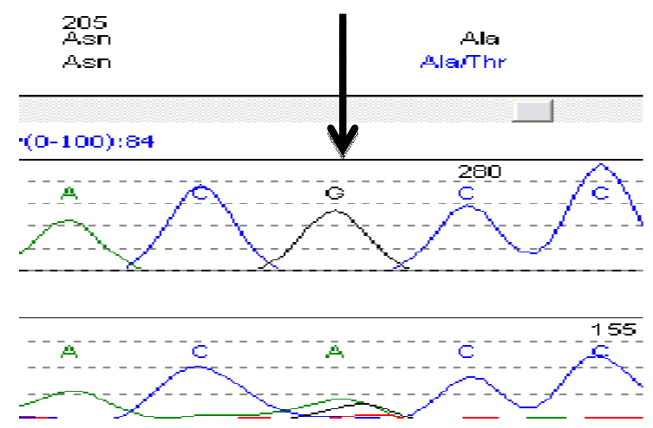

B

A 5'CGCAACGCCAGCCAT3' $\begin{array}{lllll}\mathbf{R} & \mathbf{N} & \mathbf{A} & \mathbf{S} & \mathbf{H}\end{array}$ T Human QAGYGGEACGQCGLGYFEAERNA \$HLVCSACFGPCARCSGPEES Bovine QAGYGGEACGQCGLGYFEAERNA\$HLVCSACFGPCARCSGPEES Mouse QAGYGGEACGQCGLGYFEAERNSSHLVCSACFGPCARCTGPEES

Figure 3.2: A. Sequence analysis identifying missense mutations in CRELD1. The arrow on the electropherogram indicates the variant nucleotide, with the wild-type sequence shown below. The altered nucleotide is shown in green. The single-letter amino acid translation is under the first base of each codon. The altered residue is in red. Sequences from the complementary stand showed the same heterozygous change. B. Alignment part of the sequence of CRELD domain of human with bovine and mouse. 

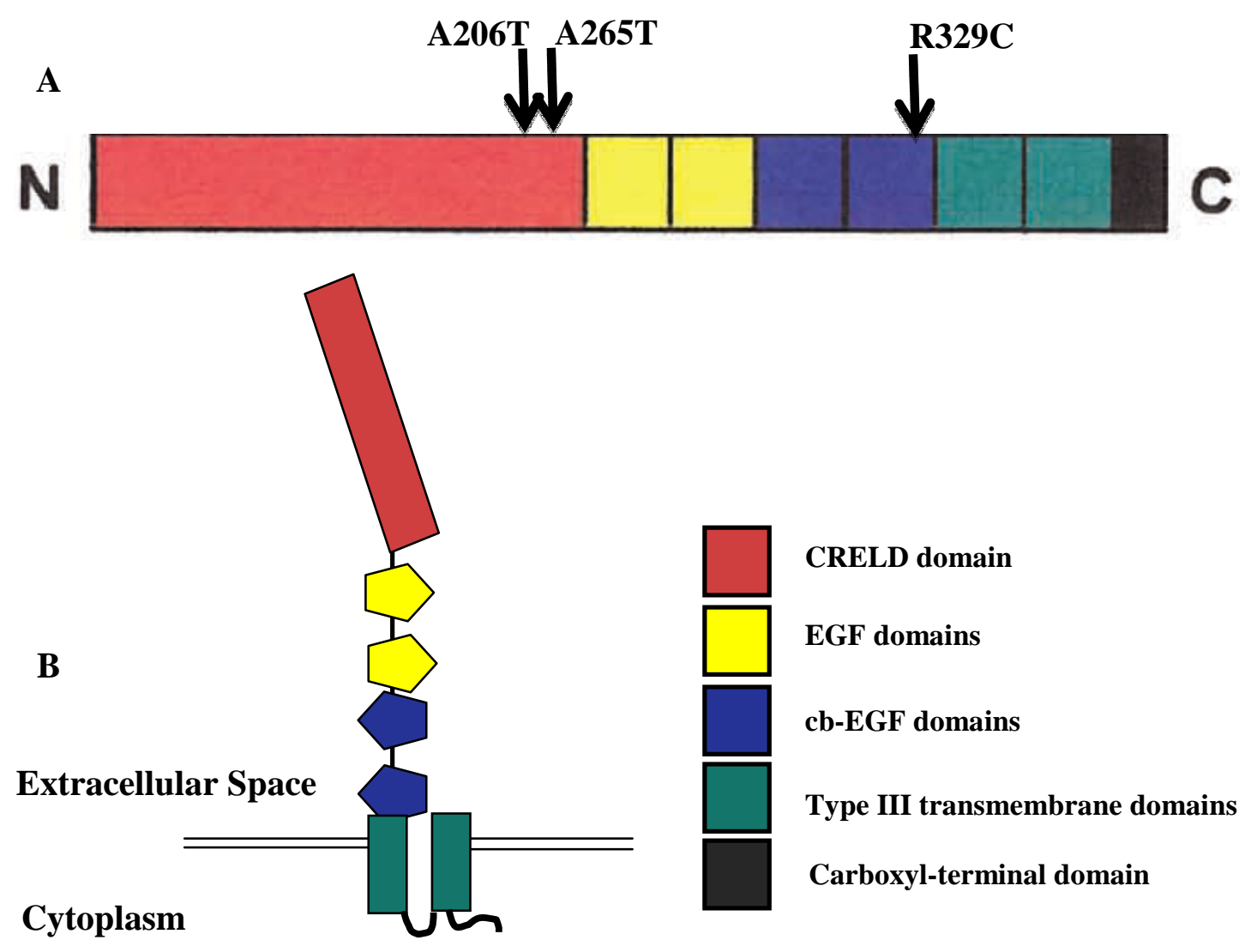

Figure 3.3: A. Diagrammatic representation of CRELD1 protein (Robinson et al., 2003). The relative position of three amino acid changes found in heterotaxy patients are indicated by the arrows above the diagram of CRELD1. B. A diagrammatic representation of CRELD1 showing the predicted domain structure and cell membrane topology (Rupp et al., 2002).

\section{2-PATIENT2-T265A MUTATION}

The second alteration was found in a South Asian Indian patient with TGA, coarctation of aorta (CoA), AVSD, and double inlet left ventricle (DILV). The single base substitution of $A$ to $\mathrm{G}$ at cDNA position 792 (c. A792G), was identified at exon 7 of DNA patient. This results in a substitution of alanine for threonine at amino acid position 265, located in the highly conserved region of the CRELD domain (Fig.3.5, 
A and B). The base substitution was not detected in 102 race-relevant control

chromosomes (personal communication, Dr. Subrata K. Dey, West Bengal

University of Technology, India). This data indicate that there is less than 5\% chance that the mutation is a polymorphism in that population with $95 \%$ confidence (Collins and Schwartz, 2002) suggesting the variation is unlikely to be a polymorphism.

Polyphen-2 analysis of mutation indicates that the mutation has a structural damaging effect on CRELD1 protein.

A

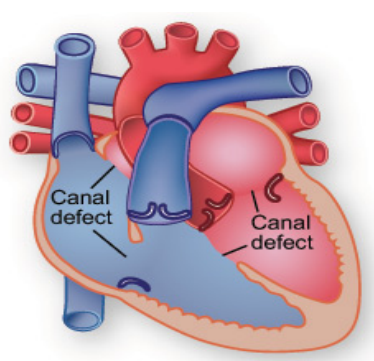

D

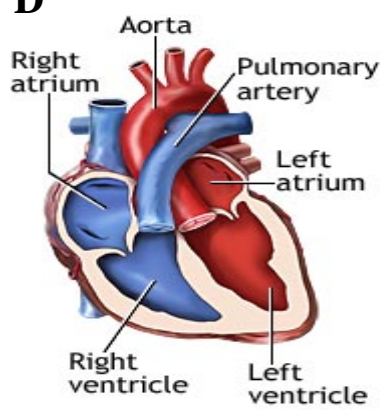

B
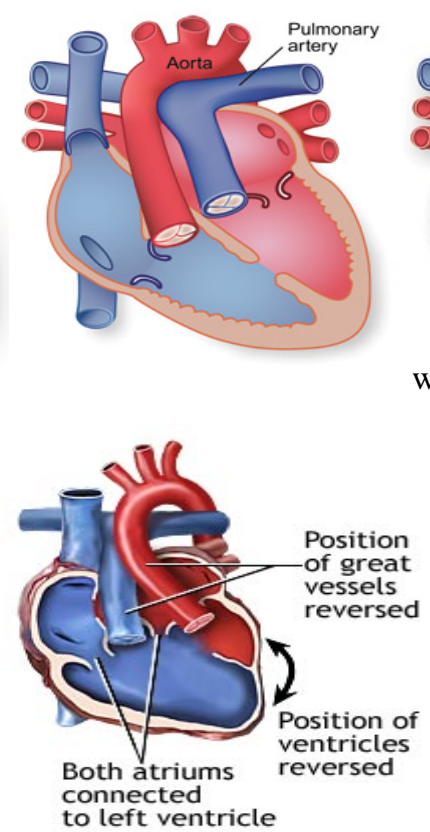
connected

left ventricle
$\mathbf{C}$

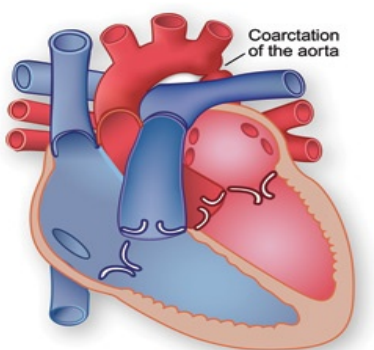

www.texasheartinstitute.org

Figure 3.4: Illustration of different heart defects. A. is showing AVSD also known as canal defect which is a defect involves holes between the two ventricles and atriums. B is showing the TGA where the positions of aorta and pulmonary artery have been reversed. The coarctation of aorta is illustrated in C. D is comparing the normal heart (on the left) with DILV (on the right) where the position of great vessels and ventricles are reversed and both atriums are connected to the left ventricle. 
A
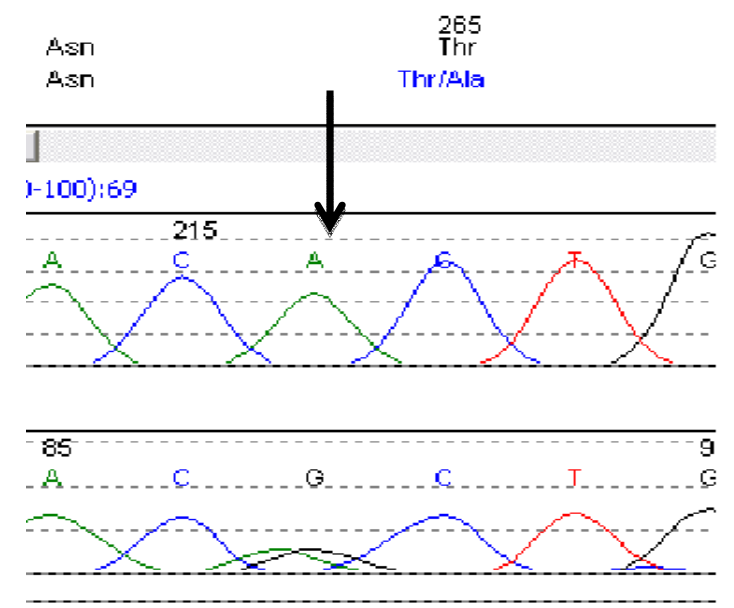

A

B

5'GCGTGAACGCTGAGG3'

$\mathrm{V} \quad \mathrm{N} \quad \mathrm{T}$ E G

A

HumanLKCVDIDECGTEGANCGADQFCVNTEGSYECRDCAKACLGCMGAGP BovineLKCVDIDECGTERASCGADQFCVN TE GSYECRDCAKACLGCMGAGP MouseLKCVDIDECGTEQATCGADQFCVN TEGSYECRDCAKACLGCMGAGP

Figure 3.5: A. Sequence analysis data, identifying the second missense mutation in CRELD1. The arrow on the electropherogram indicates the variant nucleotide, with the wild-type sequence shown below. The altered nucleotide is shown in green. The single-letter amino acid translation is under the first base of each codon. The altered residue is in red. Sequences from the complementary stand showed the same heterozygous change. B. Alignment of the sequence for the topological domain from human, bovine, and mouse CRELD1 gene. 


\section{3-PATIENT3-R329C MUTATION}

The third alteration was found in a Hispanic patient with a situs inversus, AVSD, and asplenia, a congenital absence of the spleen which is usually accompanied by complex cardiac malformations, malposition and maldevelopment of the abdominal organs, and abnormal location of the lungs (OMIM\# 208530). The patient had a family history of two female siblings who died in utero. The first sibling was diagnosed with pulmonary artery absence (PA hypoplasia), dysplastic tricuspid valve, hypoplastic thymus, asplenia; the second sibling died from cystic hygroma, and liver calcification. No samples were available from the siblings for farther study.

The mutation found in this patient results in a substitution of cysteine for arginine at amino acid 329 (R329C) in exon 9 which is located in a highly conserved region among species (Fig.3.6, A and B). This amino acid is located in the second calcium-binding EGF (cb-EGF) region, leading to change in $\beta$-sheet folding in the secondary structure of CRELD1 (Robinson et al., 2003). This is a recurrent mutation that has been identified in individuals with non-syndromic AVSD (Robinson et al), and AVSD with Down's syndrome (Maslen et al, 2004). The mutation was not detected as a polymorphism in previous studies (Robinson et al., 2003; Kusuma et al., 2011), and has been shown to change the protein conformation (Robinson et al., 2003). 
A

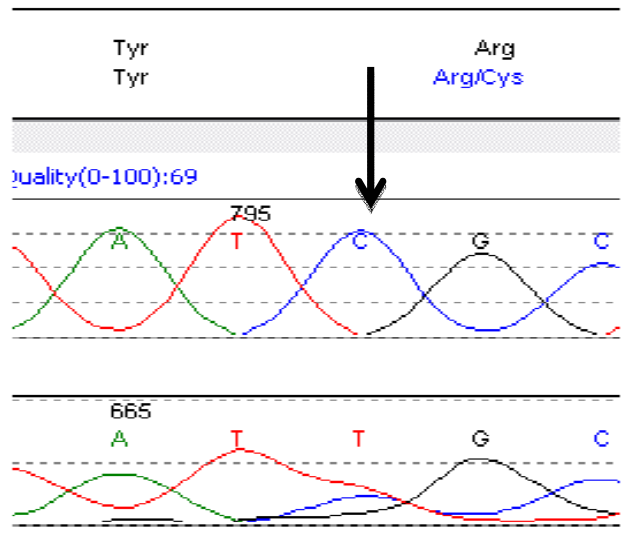

B

5'GCGGTTATCGCTGCA3'

$\begin{array}{lllll}\mathrm{G} & \mathrm{Y} & \mathbf{R} & \mathrm{C} & \mathrm{I}\end{array}$

C

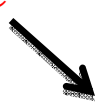

Human VDECETEVCPGENKQCENTEGG RCICAEGYKQMEGICVKEQIPESA

Bovine VDECETAVCQGENQQCENTEGS R ICADGYKQMEGICVKEQIPESA

Mouse VDECETVVCPGENEKCENTEGG RQVCAEGYRQEDGICVKEQVPESA

Figure3.6: A. Sequence analysis data, identifying the third missense mutation in CRELD1. The arrow on the electropherogram indicates the variant nucleotide, with the wild-type sequence shown below. The altered nucleotide is shown in green. The single-letter amino acid translation is under the first base of each codon. The altered residue is in red. Sequences from the complementary stands showed the same heterozygous changes. B. Alignment part of the sequence for the topological domain from human, bovine, and mouse CRELD1 gene.

\section{4-OTHER SIGNIFICANT VARIANTS IN CRELDI}

Table 3.2 summarizes the other non-synonymous and synonymous variants found in this heterotaxy population. A non-synonymous variant A to G substituting 
valine to methionine at amino acid position M13V is located in exon1. All patients' DNA samples in this study carried this SNP variant. This SNP was found in data base SNP, indicating there is a polymorphism for this variant and suggesting its benign effect on protein structure. PolyPhen-2 analysis also suggested that the mutation is unlikely to change the protein structure or function.

A two base pair GA deletion was found in chromosomes of ten patients, located at a non-coding sequence of CRELD1. The deletion is 52 base pairs upstream of the branch point located in intron eight and probably does not have a significant effect during splicing process. In addition, homozygous substitution of A for $\mathrm{G}$ at intron position G9957920A, located at intron 6, was detected in all of the patients' DNA samples. This SNP is located thirty base pair downstream of intron/exon boundaries, indicating that it is unlikely to affect splicing. No data was found in database for this SNP. Four other known SNPs (rs279552, rs57022843, rs9853613, rs2302786) were also identified for which no significant effect has been reported for them. In addition, three other rare synonymous variants L304L, P315P, and Q368Q were detected. It was observed that all three amino acids coded for CRELD1 are highly conserved among human, mouse, and bovine.

The first synonymous variant was detected as a heterozygous $\mathrm{C}$ to $\mathrm{T}$ silent mutation at L304L located at the end of the exon 8. Another heterozygous silent mutation was detected in three unrelated individuals. The variant was a substitution of $\mathrm{A}$ for $\mathrm{G}$ at amino acid position $\mathrm{P} 315 \mathrm{P}$. This amino acid is located at the second cbEGF domain of CRELD1. The last heterozygous silent mutation was found in a 
patient, changing the base pair $\mathrm{G}$ to $\mathrm{A}$ at amino acid position $\mathrm{Q} 368 \mathrm{Q}$ which is within the transmembrane domain of CRELD1. These synonymous variants were not further characterized, although it should be noted that synonymous SNPs can affect splicing via the regulation of splice enhancers or inhibitors (Parmley et al., 2006; Nielsen et al., 2007).

Table 3.2: Synonymous and non-synonymous variants in CRELDl found in the heterotaxy population

\begin{tabular}{|c|c|c|c|}
\hline Variants & Location & Functional group & Number of patients \\
\hline G>GT (heterozygous) & Promoter 2 at 9951009 & & 9 \\
\hline $\mathrm{G}>\mathrm{T}$ (homozygous) & Promoter 2 at 9951009 & & 1 \\
\hline $\mathrm{T}>\mathrm{TC}$ (heterozygous) & Promoter 2 at 9950860 & & 3 \\
\hline $\mathrm{C}>\mathrm{CT}$ (heterozygous) & Promoter 2 at 9950628 & & 1 \\
\hline $\mathrm{A}>\mathrm{G}$ (homozygous) & Exon 1, M13V & & All samples (126) \\
\hline$A>A G \& A>G$ & Intron 3 at 9954660 & & $\begin{array}{l}23 \% \text { heterozygous } \\
11 \% \text { homozygous }\end{array}$ \\
\hline G>A (homozygous) & Intron 6 at 9957920 & & All samples (126) \\
\hline C>CT (heterozygous) & Exon 8, L304L & CRELD domain & 1 \\
\hline GA deletion & Intron 8 at 9959990/1 & & 10 \\
\hline $\mathrm{G}>\mathrm{GA}$ & Exon 9, P315P & cb-EGF domain & 3 \\
\hline $\mathrm{C}>\mathrm{CT}$ (heterozygous) & Intron 9 at 9960229 & & 1 \\
\hline G>GA (heterozygous) & Exon 10 at Q368Q & Transmembrane & 1 \\
\hline
\end{tabular}




\section{CHAPTER IV: DISCUSSION}

This study demonstrates that there are missense mutations in CRELD1 that may act to increase the likelihood of AVSD or other CHD in heterotaxy patients. In this study three different heterozygous missense mutations in CRELDI were identified in three unrelated individuals from a patient population of 126 who were diagnosed with heterotaxy. Approximately $66 \%$ of the heterotaxy population had different types of heart defects (Fig.4.1, A). The three individuals carrying mutation in CRELD1 were diagnosed with different forms of heart defects in addition to AVSD which accounts for about $9 \%$ of patients with heterotaxy and heart defects (Fig.4.1, B) and approximately $6.3 \%$ in total heterotaxy population used in this study. All three mutations were identified in highly conserved regions of CRELDI and can alter CRELD1 properties. They are suggesting that mutation in CRELD1 may increase the susceptibility of CHD in the heterotaxy population.
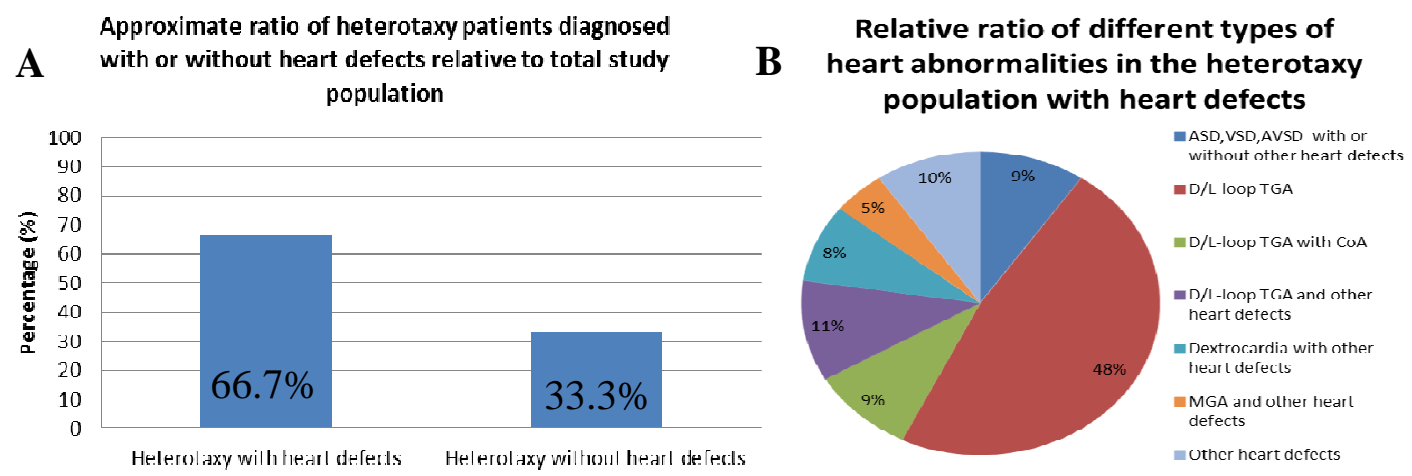

Figure 4.1: A, Approximate ratio of heterotaxy patients diagnosed with heart defects and without heart defects in study population. B, The ratio of different types of heart defects in heterotaxy patients with heart defects found in this population 
In one case the mutation was an $\mathrm{A}$ to $\mathrm{T}$ transition in exon 5 at cDNA position 615 (c. $615 \mathrm{~A}>\mathrm{G}$ ) that results in a substitution of threonine for alanine at amino acid 206 (p.A206T) in the CRELD domain of CRELD1. This domain has extracellular function and is 333 amino acids long (p. 30-362) and contains two potential N-linked glycosylation sites one at amino acid position 79 and 205. N-linked glycosylation of some membrane proteins is critical for proper folding, co-assembly and subsequent trafficking through the biosynthetic pathway, suggesting that it is necessary for proper functional role of CRELD1. The mutation changes the amino acid located at sequon position of the second $\mathrm{N}$-linked glycosylation site. The sequon position is Asn-X-Ser or Asn-X-Thr, where X is any amino acid except proline. In CRELD1 the sequon position is Asn-Ala-Ser. The mutation, A206T, changes the alanine to threonine. According to the consensus sequence $\mathrm{X}$ can be any amino acid except proline, but changes in the sequence of this sequon have shown to have a major effect on the ability of various tissues to utilize $\mathrm{N}$-linked glycosylation signals (Nishikawa and Mizun, 2001).

Therefore this alteration would not likely abolish glycosylation, but it could affect the efficiency. Using the bioinformatics tool, PolyPhen-2, suggests that this variant is unlikely to affect the protein structure. However as can be seen in Fig.4.2, the molecular formula for alanine is $\mathrm{C}_{3} \mathrm{H}_{7} \mathrm{NO}_{2}$. This amino acid is non-polar and hydrophobic and is known to be ambivalent, meaning it can be inside or outside of the protein molecule. On the other hand, threonine is slightly polar with a molecular formula of $\mathrm{C}_{4} \mathrm{H}_{9} \mathrm{NO}_{3}$, and compared to alanine it has one extra carbon and hydroxyl 
group making it a hydrophilic molecule. Although Polyphen-2 indicates that this substitution will have a benign effect on protein structure, my analysis suggests that this mutation may have the potential to significantly change the protein structure.

A

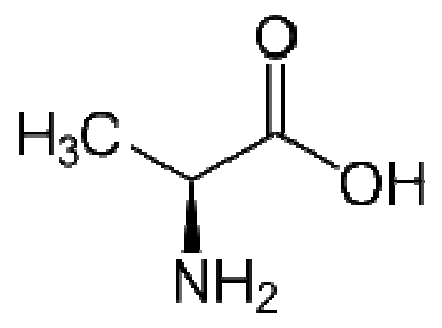

B

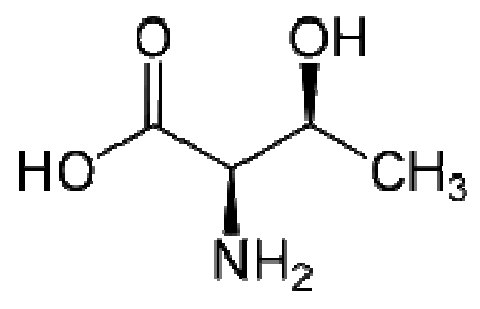

Figure 4.2: Alanine (A) and threonine (B) chemical structure.

In addition, this non-synonymous variant is located in the CRELD domain that has extracellular function and such non-conservative alteration in CRELD1 can affect its proper function. This alteration was not present in 93 race-relevant control chromosomes, indicating the novelty of this mutation and suggesting an association of risk of developing AVSD that may work in concert with addition factors such as heterotaxy in this study. Further study can be used to confirm our expectation on changes in protein structure by analyzing a recombinantly expressed mutant CRELD1 in which the physical properties of mutant protein can be compared with wild-type CRELD1.

The second mutation was a single base alteration of $A$ to $G$ at cDNA position 792 (c. A792G) causing amino acid substitution of alanine for threonine at amino acid position 265 (p. T265A). This SNP is within the exon 7 and located in a highly 
conserved region CRELD domain with extracellular function. Fig.4.2 shows the chemical structure of these two amino acids. This amino acid change will reduce the polarity of the protein and subsequently can alter its function.

Based on the analysis using PolyPhen-2, this region is highly conserved among more than 20 different species and mutation at c. 256 is predicted to have damaging effect on the protein structure. Although the specific effect of this mutation on the structure of CRELD1 is still unknown. The patient with this mutation exhibits a broad range of heart defects in heart valves and chambers in addition to TGA, AVSD, and coarctation of aorta (CoA). Race relevant population study confirmed the novelty of this mutation. This data is consistent with my hypothesis that there are mutations in CRELDI that can increase the risk of developing CHD in heterotaxy population.

The last mutation was found in a patient with situs inversus with AVSD and asplenia. The mutation is a $\mathrm{C}$ to $\mathrm{T}$ transition in exon 9 at cDNA position 985 (c.985 C>T) that results in a substitution of cysteine for arginine at amino acid 329 (p.R329C). The chemical structure of these two amino acids is shown in Fig.4.3. The mutation is in a very highly conserved region in the second cb-EGF domain of the protein. This mutation was previously detected in individuals with non-syndromic AVSD (Robinson et al., 2003) and AVSD with Down's syndrome (Maslen et al., 2006; Kusuma et al., 2011) and was determined to not be present in race-relevant control chromosomes indicating that it is a disease-specific mutation. 
CRELD1 has two highly conserved cb-EGF domains (Fig. 3.3, B). The first cb-EGF domain is 41 amino acids long, at amino acid position 153 to 193. The second cb-EGF domain consists of 40 amino acids (p.305-344). These domains have a very specific disulfide bonding pattern which is essential for proper protein function (Robinson et al., 2003). Consequently, addition of a free cysteine residue, as occurs with this mutation, change the $\beta$-sheet in the secondary structure of CRELD1 and would be expected to interfere with protein folding (Fig.4.4).

A

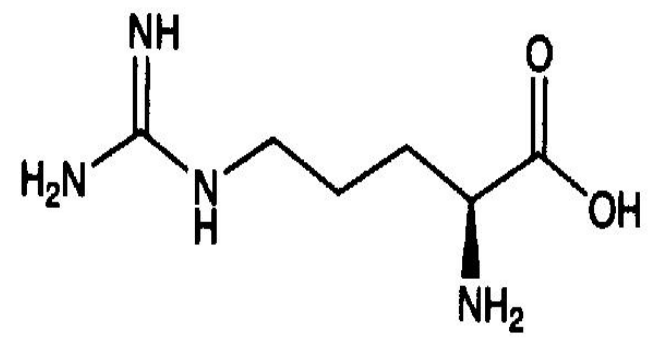

B

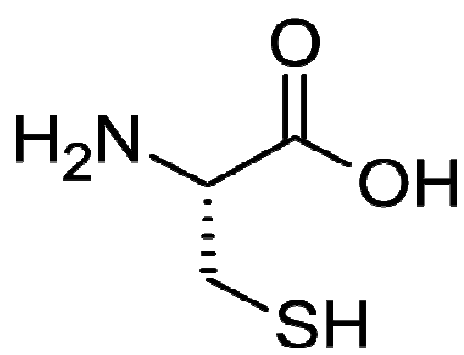

Figure 4.3: Arginine (A) and cysteine (B) chemical structure.

Accordingly, previous studies have shown that the p.R329C mutation alters the protein structure (Robinson et al., 2003). Furthermore, this amino acid position is conserved as an arginine residue among mammals (Fig.3.6, B). Taken together, these data suggest that the mutation p.R329C is involved in causing CHD in heterotaxy patients.

In this study 84 out of $126(67 \%)$ patients with heterotaxy had a broad range of heart defects. Based on this study, CRELD1 mutations had a prevalence of about 
$2.4 \%$ in total heterotaxy population. Identification of CRELD1 mutations in 3 out of 84 heterotaxy patients diagnosed with broad range of CHD suggesting the prevalence of CRELD1 mutations appears to be approximately $3.5 \%$ in heterotaxy population with different types of heart defects. In addition, all three mutations were found in patients with heterotaxy who were also diagnosed with AVSD (3/8) suggesting a high prevalence of $37.5 \%$ in this portion of the population. These data suggest that defects in CRELD1 may contribute to the pathogenesis of AVSD and CHD in the context of heterotaxy. This is consistent with previous studies that demonstrated that CRELD1 mutations were associated with AVSD and heterotaxy as well as nonsyndromic AVSD (Robinson et al., 2003; Maslen, 2004). However, the high incidence of CRELD1 mutations in individuals with heterotaxy and AVSD indicates that the heterotaxy background significantly sensitizes those individuals towards developing an AVSD since the incidence of CRELDI $1^{\text {mut }}$-associated AVSD in other populations. 


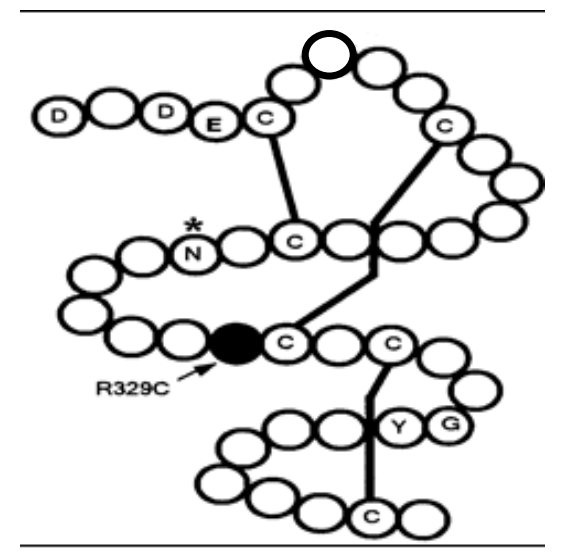

Figure 4.4: Diagrammatic representation of the two cb-EGF domain of CRELD1. The R329C mutation is indicated by the arrow. Conserved amino acidresidues defining cb-EGF domains are indicated by the single letter amino acid code. Black lines show the disulfide-bonding pattern for the conserved cysteine residues (Robinson et al., 2003).

Consequently, based on these results, I conclude that CRELDI mutations in general may increase the risk for developing an AVSD and CHD in heterotaxy patients. However, it is very important to consider that in the process of L-R asymmetry and heart development, both are following a very complicated pathway and many factors can affect their process. The question remains as to what combination(s) of factors is required to exceed the threshold causing a complete AVSD and CHD. The results of this study support the premise that mutations in CRELD1 are a risk factor for AVSD and CHD in heterotaxy population.

Previous studies suggest that combinations of rare mutations, as see in this study, in genes that control early embryonic L-R patterning and environmental factors during embryogenesis are causing most of the cases heterotaxy with heart 
defects. Future works will have to focus on studying the other candidate genes such as $N K X 2.5$ in a larger population (Belmont 2004). Such information will provide the factors effecting disease susceptibility in heterotaxy population. These can lead to the ability of early disease detection and relatively in future to therapeutic ways of restoring the function of altered genes.

\section{FUTURE STUDIES}

Mouse model can be used to study on how mutations in CRELDI would increase the risk of developing AVSD and CHD in heterotaxy population. This can

be done using F1 generation by crossing heterotaxy mouse $\mathrm{Zic}^{(+/-)}$and $\mathrm{CreldI}^{(+-)}$ mouse and studying the rate of heart defects in their progenies. In addition, more study has to focus on looking for other unknown genes that increase the susceptibility of developing AVSD and CHD in heterotaxy. 


\section{REFERENCES}

Afzelius, B.A., Mossberg, B., \& Bergstrom S.E. 2001. Immotile cilia syndrome (primary ciliary dyskinesia), including Kartagener syndrome. The Metabolic and Molecular Bases of Inherited Disease, eds. Scriver, C. R., Beaudet, A. L., Sly, W. S. \& Valle, D. (McGraw-Hill, New York), pp. 4817-27

Ansley, S.J., Badano, J.L., Blacque, O.E., Hill, J., Hoskins, B.E., Leitch, C.C., Kim, J.C., Ross, A.J., Eichers, E.R., Teslovich, T.M., Mah, A.K., Johnsen, R.C., Cavender, J.C., Lewis, R.A., Leroux, M.R., Beales, P.L., Katsanis, N. 2003. Basal body dysfunction is a likely cause of pleiotropic Bardet-Biedl syndrome. Nature, 425, 628-33.

Aruga, J. 2004. The role of Zic genes in neural development. Molecular and Cellular Neurosciences, 26, 205-21.

Aruga, J., Kamiya, A., Takahashi, H., Fujimi, T.J., Shimizu, Y., Ohkawa, K., Yazawa, S., Umesono, Y., Noguchi, H., Shimizu, T., Saitou, N., Mikoshiba, K., Sakaki, Y., Agata, K., Toyoda, A. 2006. A wide-range phylogenetic analysis of Zic proteins: implications for correlations between protein structure conservation and body plan complexity. Genomics, 87, 78392.

Aruga, J., Nagai, T., Tokuyama, T., Hayashizaki, Y., Okazaki, Y., Chapman, VM., Mikoshiba, K. 1996. The mouse zic gene family. Homologues of the Drosophila pair rule gene odd-paired. Journal of Biological Chemistry, 271,1043-1047.

Aruga, J., Ogura, H., Shutoh, F., Ogawa, M., Franke, B., Nagao, S., Mikoshiba, K. 2004. Locomotor and oculomotor impairment associated with cerebellar dysgenesis in Zic3-deficient (Bent tail) mutant mice. The European Journal of Neurosciences, 20, 2159-67.

Attisano, L. and Wrana, J.L. (2002) Signal transduction by the TGF-beta superfamily. Science, 296, 1646-1647.

Aw, S. and Levin, M. 2009. Is left-right asymmetry a form of planar cell polarity? Development, 136, 355-66.

Aylsworth, A.S. 2001. Clinical aspects of defects in the determination of laterality. American Journal of Medical Genetics, 101, 345-355. 
Bamford, R.N., Roessler, E., Burdine, R.D., Saplakoglu, U., dela Cruz, J.,Splitt, M., Goodship, J.A., Towbin, J., Bowers, P., Ferrero, G.B. et al. 2000. Loss-offunction mutations in the EGF-CFC gene CFC1 are associated with human left-right laterality defects. Nature Genetics, 26, 365-369.

Beales, P.L. 2005. Lifting the lid on Pandora's box: the Bardet-Biedl syndrome. Current Opinions on Genetic Development, 15, 315-323.

Belmont, J.W., Mohapatra, B., Towbin, J.A. \& Ware, S.M. 2004. Molecular genetics of heterotaxy syndromes. Current Opinion on Cardiology,19, 216-20.

Berg, C., Geipel, A., Smrcek, J., Krapp, M., Germer, U., Kohl, T., Gembruch, U., Baschat, A.A. 2003. Prenatal diagnosis of cardiosplenic syndromes: a 10year experience. Ultrasound in Obstetrics and Gynecology, 5,451-9.

Bianco, C., Adkins, H.B., Wechselberger, C., Seno, M., Normanno, N., De Luca, A., Sun, Y., Khan, N., Kenney, N., Ebert, A., Williams, K.P., Sanicola, M., Salomon, D.S. 2002. Cripto-1 activates nodal- and ALK4-dependent and -independent signaling pathways in mammary epithelial cells. Molecular and Cellular Biology, 22,2586-2597.

Bisgrove, B.W., Morelli, S.H., Yost, H.J. 2003.Genetics of human laterality disorders: Insights from vertebrate model systems. Annual Review of Genomics and Human Genetics, 4,1-32.

Bisgrove, B.W., Yost, H.J.2001. Classification of left-right patterning defects in zebra fish, mice, and humans. American Journal of Medical Genetics, 101, 315-23.

Carrel, T., Purandare, S.M., Harrison, W., Elder, F., Fox, T., Casey, B., Herman, G.E. 2000. The X-linked mouse mutation Bent tail is associated with a deletion of the Zic3 locus. Human Molecular Genetics, 12, 1937-42.

Casey, B., Devoto, M., Jones, K.L., Ballabio, A. 1993. Mapping a gene for familial situs abnormalities to human chromosome Xq24-q27.1. Nature Genetics, 5, 403-7.

Chhin, B., Hatayama, M., Bozon, D., Ogawa, M., Schön, P., Tohmonda, T., Sassolas, F., Aruga, J., Valard, A.G., Chen, S.C., Bouvagnet, P. 2007. Elucidation of penetrance variability of a ZIC3 mutation in a family with complex heart defects and functional analysis of ZIC3 mutations in the first zinc finger domain. Human Mutation, 8, 563-70 
Collins, J.S., Schwartz, C.E. 2002. Detecting polymorphisms and mutations in candidate genes. American Journal of Human Genetics, 71, 1251-1252

Conlon, F.L., Lyons, K.M., Takaesu, N., Barth, K.S., Kispert, A., Herrmann, B. and Robertson, E.J. 1994. A primary requirement for nodal in the formation and maintenance of the primitive streak in the mouse. Development, 120, 19191928.

Ferrero, G.B, Gebbia, M., Pilia, G., Witte, D., Peier, A., Hopkin, R.J., Craigen, W.J., Shaffer, L.G., Schlessinger, D., Ballabio, A., Casey, B. 1997. A submicroscopic deletion in Xq26 associated with familial situs ambiguus. American Journal of Human Genetics, 61, 395-40.

Fritz, B., Kunz, J., Knudsen, G.P., Louwen, F., Kennerknecht, I., Eiben, B., Orstavik, K.H., Friedrich, U., Rehder, H. 2005. Situs ambiguus in a female fetus with balanced (X;21) translocation--evidence for functional nullisomy of the ZIC3 gene? European Journal of Human Genetics, 13, 34-40.

Gebbia, M., Ferrero, G.B., Pilia, G., Bassi, M.T., Aylsworth, A., Penman-Splitt, M., Bird, L.M., Bamforth, J.S., Burn, J., Schlessinger, D., Nelson, D.L., Casey, B. 1997.X-linked situs abnormalities result from mutations in ZIC3. Nature Genetic, 17, 305-8

Goldmuntz, E., Bamford, R., Karkera, J.D., dela Cruz, J., Roessler, E. and Muenke, M. 2002. CFC1 mutations in patients with transposition of the great arteries and double-outlet right ventricle. American Journal of Human Genetics, 70, 776-780.

Grinberg, I. and Millen, K. J. 2005. The ZIC gene family in development and disease. Clinical Genetics, 67, 290-296.

Hamada, H., Meno, C., Watanabe, D. and Saijoh, Y. 2002. Establishment of vertebrate left-right asymmetry. Nature Reviews Genetics, 3, 103-113.

Harvey, R.P. 1998. Links in the left/right axial pathway. Cell, 94, 273-276.

Herman, G.E., El-Hodiri, H.M. 2002. The role of ZIC3 in vertebrate development. Cytogenetic and Genome Research, 99, 229-35.

Hirokawa, N., Tanaka, Y., Okada, Y., Takeda, S. 2006. Nodal flow and the generation of left-right asymmetry. Cell, 125, 33-45. 
Jaeggi, E.T., Hornberger, L.K., Smallhorn, J.F., Fouron, J.C. 2005. Prenatal diagnosis of complete atrioventricular block associated with structural heart disease: combined experience of two tertiary care centers and review of the literature. Ultrasound in Obstetrics and Gynecology, 26, 16-21.

Kathiriya, I.S. and Srivastava, D., 2000. Left-right asymmetry and cardiac looping: implications for cardiac development and congenital heart disease. American Journal of Medical. 97, 271-279.

Klootwijk, R., Franke, B., van der Zee, C.E., de Boer, R.T., Wilms,W., Hol, F.A., Mariman, E.C. 2000. A deletion encompassing Zic3 in Bent tail, a mouse model for X-linked neural tube defects. Human Molecular Genetics, 9, 1615162.

Kosaki, K., Casey, B. 1998. Genetics of human left-right axis malformations. Seminar in Cell and Developmental Biology, 9, 89-99.

Kosaki, R., Gebbia, M., Kosaki, K., Lewin, M., Bowers, P., Towbin, J.A. and Casey, B. 1999. Left-right axis malformations associated with mutations in ACVR2B, the gene for human activin receptor type IIB. American Journal of Medical Genetics, 82, 70-76.

Krebs, L.T., Iwai, N., Nonaka, S., Welsh, I.C., Lan, Y., Jiang, R., Saijoh, Y., O'Brien, T.P., Hamada, H., Gridley, T. 2003. Notch signaling regulates leftright asymmetry determination by inducing Nodal expression. Genes and Development, 17, 1207-1212.

Kuehl, K.S., Loffredo, C. 2002. Risk factors for heart disease associated with abnormal sidedness. Teratology, 66,242-248

Kusuma, L., Dinesh, S.M., Savitha, M.R., Krishnamurthy, B., Narayanappa, D., Ramachandra, N. 2011. A maiden report on CRELD1 single-nucleotide polymorphism association in congenital heart disease patients of Mysore, South India. Genetic Testing and Molecular Biomarkers, Epub ahead of print.

Levin, M. 2005. Left-right asymmetry in embryonic development: A comprehensive review. Mechanisms of Development, 122, 3-25.

Leyva-Vega, M., Gerfen, J., Thiel, B. D., Jurkiewicz, D., Rand, E. B., Pawlowska, J., Kaminska, D., Russo, P., Gai, X., Krantz, I. D., Kamath, B. M., Hakonarson, H., Haber, B. A. \& Spinner, N. B. 2010. Genomic alterations in biliary atresia suggest region of potential disease susceptibility in 2q37.3. American Journal of Medical Genetics. 152A, 886-895. 
Lin, A.E., Ticho, B.S., Houde K., Westgate, M.N. \& Holmes L.B. 2000. Heterotaxy: Associated conditions and hospital-based prevalence in newborns. Genetics in Medicine, 2, 157-172.

Lowe, L.A., Supp, D.M., Sampath, K., Yokoyama, T., Wright, C.V., Potter, S.S., Overbeek, P. and Kuehn, M.R. 1996. Conserved left-right asymmetry of nodal expression and alterations in murine situs inversus. Nature, 381, 158161.

McGrath, J., Somlo, S., Makova, S., Tian, X., Brueckner, M. 2003. Two populations of node monocilia initiate left-right asymmetry in the mouse. Cell, 114, 6173.

Megarbane, A., Salem, N., Stephan, E., Ashoush, R., Lenoir, D., Delague, V., Kassab, R., Loiselet, J., Bouvagnet, P. 2000. X-linked transposition of the great arteries and incomplete penetrance among males with a nonsense mutation in ZIC3. European Journal of Human Genetics, 8, 704-708.

McGrath, J., Somlo, S., Makova, S., Tian, X., Brueckner, M. 2003. Two populations of node monocilia initiate left-right asymmetry in the mouse. Cell, 114, 6173.

Maslen, C.L., Babcock, D., Robinson, S.W., Bean, L.J., Dooley, K.J., Willour, V.L., and Sherman, S.L. 2006. CRELD1 mutations contribute to the occurrence of cardiac atrioventricular septal defects in Down syndrome. American Journal of Medical Genetics, 140, 2501-2505.

Maslen, C.L. 2004. Molecular genetics of atrioventricular septal defects. Current Opinion in Cardiology, 19, 205-10

Mercola, M. and Levin, M. 2001. Left-right asymmetry determination in vertebrates. Annual Review of Cell and Developmental Biology, 17, 779-805.

Mizugishi, K., Aruga, J., Nakata, K., Mikoshiba, K. 2001. Molecular properties of Zic proteins as transcriptional regulators and their relationship to GLI proteins. Journal of Biological Chemistry, 276,2180-2188.

Mohapatra, B., Casey, B., Li, H., Ho-Dawson, T., Smith, L., Fernbach, S.D., Molinari, L., Niesh, S.R., Jefferies, J.L., Craigen, W.J., Towbin, J.A., Belmont, J.W., Ware, S.M. 2009. Identification and functional characterization of NODAL rare variants in heterotaxy and isolated cardiovascular malformations. Human Molecualr Genetics, 18, 861-71. 
Morelli, S.H., Young, L., Reid, B., Ruttenberg, H., Bamshad, M.J. 2001. Clinical analysis of families with heart, midline, and laterality defects. American Journal of Medical Genetics, 101, 388-392.

Nielsen,C.B., Shomron, N., Sandberg, R., Hornstein, E., Burge, C.B. 2007. Determinants of targeting by endogenous and exogenous microRNAs and siRNAs. RNA Society, 13, 1894-1910

Nishikawa, A, and Mizuno, S. 2001. The efficiency of N-linked glycosylation of bovine DNase I depends on the Asn-Xaa-Ser/Thr sequence and the tissue of origin. Journal of Biochemistry, 355, 245-248.

Nystul, T.G., and Spradling, A.C. 2009. Epithelial stem cells of the Drosophila ovary utilize basolateral junctions to maintain a "dynamic niche" and to suppress tumorgenesis. American Society for Cell Biology, 48th Annual Meeting.

Okada Y, Takeda S, Tanaka Y, Belmonte JC, Hirokawa N. 2005. Mechanism of nodal flow: A conserved symmetry breaking event in left-right axis determination. Cell, 121, 633-644.

Otto, E.A., Schermer, B., Obara, T., O'Toole, J.F., Hiller, K.S., Mueller, A.M., Ruf, R.G., Hoefele, J., Beekmann, F., Landau, D., Foreman, J.W., Goodship, J.A., Strachan, T., Kispert, A., Wolf, M.T., Gagnadoux, M.F., Nivet, H.,Antignac, C., Walz, G., Drummond, I.A., Benzing, T., Hildebrandt, F. 2003. Mutations in INVS encoding inversin cause nephronophthisis type 2, linking renal cystic disease to the function of primary cilia and left-right axis determination. Nature Genetics, 34, 413-20.

Pan, J., Wang, Q., Snell, W.J. 2005. Cilium-generated signaling and cilia-related disorders. Lab Investigation; A Journal of Technical Method and Pathology, 85, $452-63$.

Parmley, J.L., Chamary, J.V., Hurst, L.D. 2006. Evidence for purifying selection against synonymous mutations in mammalian exonic splicing enhancers. Molecular Biology in Evolution, 23, 301-30.

Peeters, H., Debeer, P., Bairoch, A., Wilquet, V., Huysmans, C., Parthoens, E., Fryns, J.P., Gewillig, M., Nakamura, Y., Niikawa, N., Van de Ven, W., Devriendt, K.2003. PA26 is a candidate gene for heterotaxia in humans: identification of a novel PA26-related gene family in human and mouse. Human Genetics, 112, 573-580. 
Peeters, H., Voz, M.L., Verschueren, K., De Cat, B., Pendeville, H., Thienpont, B., Schellens, A., Belmont, J.W., David, G., Van De Ven, W.J., Fryns JP,Gewillig M, Huylebroeck D, Peers B, Devriendt K. 2006. Sesn1 is a novel gene for left-right asymmetry and mediating nodal signaling. Human Molecular Genetics, 15, 3369-3377.

Pogoda, H.M., Solnica-Krezel, L., Driever, W. and Meyer, D. 2000. The zebrafish forkhead transcription factor FoxH1/Fast1 is a modulator of nodal signaling required for organizer formation. Current Biology, 10, 1041- 1049.

Przemeck, G.K., Heinzmann, U., Beckers, J., Hrabe, de Angelis. M. 2003. Node and midline defects are associated with left-right development in Delta1 mutant embryos. Development, 130, 3-13.

Purandare, S.M., Ware, S.M., Kwan, K.M., Gebbia, M., Bassi, M.T., Deng, J.M., Vogel, H., Behringer, R.R., Belmont, J.W., Casey, B. 2002. A complex syndrome of left-right axis, central nervous system and axial skeleton defects in Zic3 mutant mice. Development, 129, 2293-2302.

Redig, J.K., Fouad, G.T., Reshey, B., Babcock, D., Maslen, C.L. 2011. Mouse knockout of a unique protein, Creldl, provides novel insights into developmental and adult diseases. Submitted.

Robinson, S.W., Morris, C.D., Goldmuntz, E., Reller M.D., Jones, M.A., Steiner, R.D., Maslen, C.L. 2003. Missense Mutations in CRELD1 Are Associated with Cardiac Atrioventricular Septal Defects. American Journal of Human Genetics, 72, 104-1052.

Roessler, E., Ouspenskaia, M.V., Karkera, J.D., Velez, J.I., Kantipong, A., Lacbawan, F., Bowers, P., Belmont, J.W., Towbin, J.A., Goldmuntz, E., Feldman, B., Muenke, M. 2008. Reduced NODAL signaling strength via mutation of several pathway members including FOXH1 is linked to human heart defects and holoprosencephaly. American Journal of Human Genetics, 83, 18-29.

Ruppa, P.A., Fouada, G.T., Egelstona, C.A., Reifstecka, C.A, Olsona, S.B, Knospa, W.M., Glanvilleb, R.W., Thornburgb, B.C., Robinsonb S.W., Maslen, C.L. 2002. Identification, genomic organization and mRNA expression of CRELD1, the founding member of a unique family of matricellular proteins. Clinical Genetics. 293, 1-2. 
Saijoh, Y., Adachi, H., Sakuma, R., Yeo, C.Y., Yashiro, K., Watanabe, M., Hashiguchi, H., Mochida, K., Ohishi, S., Kawabata, M. et al. 2000. Left-right asymmetric expression of lefty 2 and nodal is induced by a signaling pathway that includes the transcription factor FAST2. Molecualr Cell, 5, 35-47.

Schier, A.F. and Shen, M.M. 2000. Nodal signaling in vertebrate development. Nature, 403, 385-389.

Schier, A.F. 2003. Nodal signaling in vertebrate development. Annual Review of Cell and Developmental Biology, 19, 589-621.

Selamet Tierney, E.S., Marans, Z., Rutkin, M.B. and Chung, W.K. 2007. Variants of the CFC1 gene in patients with laterality defects associated with congenital cardiac disease. Cardiology in the Young, 17, 268-274.

Song, M.S., Hu, A., Dyhamenahali, U., Chitayat, D., Winsor, E.J., Ryan, G., Smallhorn, J., Barrett, J., Yoo, S.J., Hornberger, L.K. 2009. Extracardiac lesions and chromosomal abnormalities associated with major fetal heart defects: Comparison of intrauterine, postnatal and postmortem diagnoses Ultrasound in Obstetrics and Gynecology, 33, 552-559.

Sutherland, M.J., and Ware, S.M. 2009. Disorders of left-right asymmetry: heterotaxy and situs inversus. American Journal of Human Genetics, 151C, 307-17.

Takeuchi, J.K., Lickert, H., Bisgrove, B.W., Sun, X., Yamamoto, M., Chawengsaksophak, K., Hamada, H., Yost, H.J., Rossant, J., Bruneau, B.G. 2007. Baf60c is a nuclear Notch signaling component required for the establishment of left-right asymmetry. The Proceedings of the National Academy of Sciences Online (U.S.), 104, 846-51

Tzschach, A., Lenzner, S., Moser, B., Reinhardt, R., Chelly, J., Fryns, J.P., Kleefstra, T., Raynaud, M., Turner, G., Ropers, H.H., Kuss, A., Jensen, L.R. 2006. Novel JARID1C/SMCX mutations in patients with X-linked mental retardation. Human Mutation, 27, 389.

Vitale, E., Brancolini, V., De Rienzo, A., Bird, L.,Allada, V., Sklansky, M., Chae, C.U., Ferrero, G.B., Weber, J., Devoto, M., Casey, B. 2001. Suggestive linkage of situs inversus and otherleft-right axis anomalies to chromosome. Journal of Medical Genetics, 38, 182-185. 
Ware, S.M. and Belmont J.W. 2004. ZIC3, CRC1, ACVR2B, and EBAF and the visceral heterotaxies; in Epstein C, Erickson R, Wynshaw-Boris A (eds): Inborn errors of development. Oxford: Oxford University Press, 300-313.

Ware, S., Belmont, J. 2008. ZIC3, CFC1, ACVR2B, LEFTY2 and the visceral heterotaxies. In: Epstein C, Erickson R, Wynshaw-Boris A, editors. Inborn errors of development: The molecular basis of clinical disorders of morphogenesis. NewYork: Oxford University Press, 373-382.

Ware, S.M., Peng, J., Zhu, L., Fernbach, S., Colicos, S., Casey, B., Towbin, J., Belmont, J.W. 2004.Identification and functional analysis of ZIC3 mutations in heterotaxy and related congenital heart defects. American Journal of Human Genetics, 74, 93-105.

Ware, S.M., Harutyunyan, K.G., Belmont, J.W. 2006. Heart defects in X-linked heterotaxy: evidence for a genetic interaction of Zic3 with the nodal signaling pathway. Developmental dynamics, 235, 1631-7.

Watanabe, Y., Benson, D.W., Yano, S., Akagi, T., Yoshino, M., Murray, J.C. 2002. Two novel frameshift mutations in $N K X 2.5$ result in novel features including visceral inversus and sinus venosus type ASD. Journal of Medical Genetics, 39, 807-811.

Wessels, M.W., De Graaf, B.M., Cohen-Overbeek, T.E., Spitaels, S.E., de Groot-de Laat, L.E., Ten Cate, F.J., Frohn-Mulder, I.F., de Krijger, R., Bartelings, M.M., Essed, N., Wladimiroff, J.W., Niermeijer, M.F., Heutink, P., Oostra, B.A., Dooijes, D., Bertoli-Avella, A.M., Willems, P.J. 2008. A new syndrome with noncompaction cardiomyopathy, bradycardia, pulmonary stenosis, atrial septal defect and heterotaxy with suggestive linkage to chromosome $6 \mathrm{p}$.

Human Genetics, 122, 595-603.

Whitman, M. 2001. Nodal signaling in early vertebrate embryos: themes and variations. Developmental Cell, 1, 605-617.

Winer-Muram, H.T. 1995. Adult presentation of heterotaxic syndromes and related complexes. Journal of Thoracic Imaging, 10, 43-57.

Xiang, R., and Zhao, S. 2009. RTN3 inducing apoptosis is modulated by an adhesion protein CRELD1. Molecular and Cellular Biochemistry, 331, 225-230.

Xu, Q.Y., Gao, Y., Liu, Y., Yang, W.Z., and Xu, X.Y. 2008. Identification of differential gene expression profiles of radioresistant lung cancer cell line 
established by fractionated ionizing radiation in vitro. Chinese Medical Journal, 121, 1830-1837.

Yamamoto, M., Meno, C., Sakai, Y., Shiratori, H., Mochida, K., Ikawa, Y., Saijoh, Y. and Hamada, H. 2001. The transcription factor FoxH1 (FAST) mediates Nodal signaling during anterior-posterior patterning and node formation in the mouse. Genes and Development, 15, 1242-1256.

Yan, Y.T., Liu, J.J., Luo, Y., Chaosu, E., Haltiwanger, R.S., Abate-Shen, C. and Shen, M.M. .2002. Dual roles of Cripto as a ligand and coreceptor in the nodal signaling pathway. Molecualr and Cellular Biology, 22, 4439-4449.

Zhu, L., Belmont, J.W., Ware S.M. 2006. Genetics of Human Heterotaxias. European Journal of Human Genetics. 14, 17-25.

Zhou, X., Sasaki, H., Lowe, L., Hogan, B.L. and Kuehn, M.R. 1993. Nodal is a novel TGF-beta-like gene expressed in the mouse node during gastrulation. Nature, 361, 543-547. 
Appendix: CRELD1 genomic sequence.

\section{acgt $=\mathbf{R}$ seq primer}

$\underline{\operatorname{acgt}}=\mathbf{F}$ pcr primer acgt $=$ F seq primer

\section{CRELD1 Genomic}

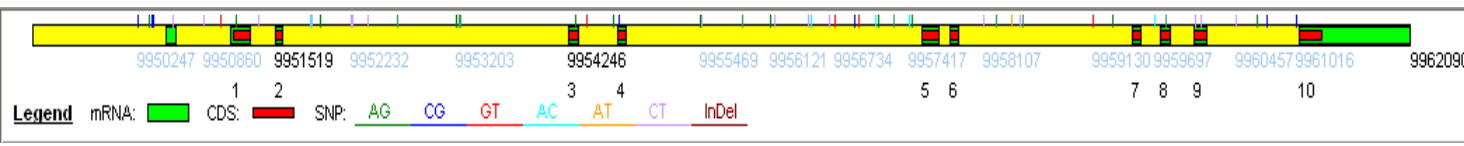

9949321 ctggcetgcc tactctttgc cgctgcgett tccctcatcc tccttctcaa aaaggatcac

9949261 gtttctaact cttcttctct gggtctccca gacatccaca agcgetgggc cctcgtgtgg

9949381 gcgaaaggtg agcgettccc ggctccccat tcccetgggg gaggaccaga gtggetgtgg

9949441 gagttctccg agggaaagcg geggccgagc tcactggetg cctccgecce tctcccetaa

9949501 cagggtggct gaggctcttg aaacaggacg tccgctcggg gggtgagtgg gagcaagcgc

9949561 tgggcggagg gccgcccccg gggagccagg cctgtgccag ctcacctctt ccctccccat

9949621 ctgttttctc cggcagcggc cgccaggggc cgcgcggctc tgctcctcta ctcagccgat

9949681 gactcgggtt tcgagcgcct ggtgggcgcc ctggcgtcgg cectgtgcca getgccgetg

9949741 cgcgtggccg tagacctgtg gagccgtcgt gaactgagcg cgcaggggec cgtggcttgg

9949801 tttcacgcgc agcggcgcca gaccctgcag gagggcggcg tggtggtctt gctcttctct

9949861 cccggtgcgg tggcgctgtg cagcgagtgg ctacaggatg gggtgtccgg gcccggggcg

9949921 cacggcccgc acgacgcctt ccgcgectcg ctcagctgcg tgctgccega cttcttgcag

9949981 ggccgggcgc ccggcagcta cgtgggggcc tgcttcgaca ggetgetcca cccggacgcc

9950041 gtacccgccc ttttccgcac cgtgcccgtc ttcacactgc cetcccaact gccagacttc

Pro1F

Pro1Fseq

9950101 ctgggggccc tgcagcagcc tcgcgccccg cgttccgggc ggctccaaga gagagcggag

9950161 caagtgtccc gggeccttca gccagccetg gatagctact tccatccccc ggggactccc

9950221 gcgccgggac gcggggtggg accaggcgcg ggacctgggg cgggggacgg gacttaata

Pro 1

9950281 aaggcagacg ctgtttttct acccatgtgg cccacacgcg tctccgtttc agtggcgggg

9950341 ctggcaaacg tcattcccta gccccgcggc cctttaaagc ccggacaggt gcagctcggt

9950401 gccgcetctg gttggctggc gtggggtgac gtaatggcac atggeccgtc gccattggct

9950461 gggcggcaag ctccgcCCCC tggactgcgg cgcgggtggg ggttgTGCGT TTTACGCAGG

9950521 CTGTGGCAGC GACGCGGTGA GGAGACGGCC CACGGCGCCC GCGGGCTGGG GCGGTCGCTT

9950581 CTTCCTTCTC CGTGGCCTAC GAGGgtctgg atccttctct gecggetcgt gggccgtgcC

Pro2F

Pro2Fseq

Pro1R

Pro1Rseq

Pro2Rseq

Pro2R

E1Rseq
9950641 tttgcecttc tgcgaggcce tgaatctgat cccttccett catatccgga tccgggctcc

9950701 tccetccaag cccggggttc cggacacctc ccccaagaca acccetctgg cetcctctcc

9950761 ttcagtact ggaatctgat ctcttctccc taattctgcg gatccggecc ctaatattct

9950821 ttatcagacc ctcagacaag aggctgactt ctgccccett gtcaaggagc gaggccactt

9950881 tcctctccac cccatgctag cgaggataac ttatttctct tctggaattg catcttatgc

9950941 gcctttcccc acccatcccc acagcccetg caatacccag tttggectct tttgcttgta

9951001 ataacgcaga tcccagcgec acggcacctt agaacagacc tttttctttc tcgcgtgggg

9951061 cctgactcct tcagtgaagc ctctccacgc cetctatctg cagGTCCCCA GCCTGGGTAA

9951121 AgAtgGCCCC ATGgCCCCCG AAgGgCCTAg tCCCAGCTAt GCTCTGgGgC CTCAgCCTCt

9951181 TCCTCAACCT CCCAGGACCT ATCTGGCTCC AGCCCTCTCC ACCTCCCCAG TCTTCTCCCC

9951241 CGCCTCAGCC CCATCCGTGT CATACCTGCC GGGGACTGGT TGACAGCTTT AACAAGgtgg

9951301 gtgcaccggc agcctcgtta gaggggaaca cagcgattta gagtggggaa ctctgggatg

9951361 caaatctgcg tggatttaag tttcatcttg gtctcttact agttgtatgg ccctaggcag

9951421 gttgccttc tgtgcctcag tttcctagtc agtagaacag tgaagtgcta gcatgtgcca

\section{0}

$$
\text { (1) }
$$


9951481 ggcactgtac ttagctatta ctaattttct gtttccagGG CCTGGAGAGA ACCATCCGGG

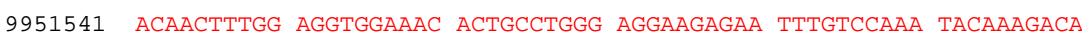

E2Rseq E1-2R

9951601 Ggtaaggggc tgctggggga aggggtgtat attcccctcc ccgccaatc tctgctctgc

9951661 tggtgtaggg ctaggaactc ttggggagca cttattcatt caacaaatag cactgaacat

9951721 ctatagtata gcagtaaaca aggcaagcaa aatgccccet tcctggagct cacattctag

9951781 tagagaagac aagcagtgaa tgagtaagtg aataatatta tgtcagatga agaacaaaca

9951841 gtgaagcacg gtagactgca ggacggtggg aggcaaggtg ttcaaggttt ggcatttgaa

9951901 cagagagaca ggaagtgaag aagcgagcta tgtgacaggg agggaattgg gcagaggatg

9951961 ggactgagct tggtgtattt gagaagtggc tggagtggag tgagccaagg ggagagtgct

9952021 agaaggtgaa ggcaaaggct taagcctcga gggctacaga aaagagttta gattttttt

9952081 ggagtgtaat gggaagctct tggaaggcta tgagcagaaa aagtgatact gtcttctcta

9952141 caccttaaa gattactcac actgctatgt agcaaacgga ttgtaagggg caagggcgga

9952201 ggaagcaggg agaccagttt gggaggcaag tgcatcatct aggtacaaag gcaacacaag

9952261 ctagtgtggt atctagtgga ggacatgatg aagaggtcac agtctgggta tattttgcag

9952321 agagaacaat aggacctggt gatagattca ttatgggtat agagaaacag tagaataaaa

9952381 gatgcttact agattttggg cctgagcaac tgggtgagta gtgcagctgt tttctaagat

9952441 ggtgagatgc gaaaccgaga aggtttaggg gaggggtggg atgtggtgtt ctttgaacgt

9952501 attgggctga aatgtccatt agacatccag gtagactcca tacaaatctg gaattcagaa

9952561 aagagtagga attggaaaca ggaatttgag agttgtcatt atatagtcag tatgtaaga

9952621 aagccatggg aaggatacag aaagccatta tatagtcaat atatgtaata cagaagcca

9952681 tttatatagt cagtatgtaa agaaaggcat gggaaggata cagaaaggcg agccctgagc

9952741 cctccagctt ttcaaagtca gatggaagag gagtcagcaa aggctcagag ttagacctgg

9952801 ttgtcggttc ttaacctctc agagccacag tttcttcacc tgtaaaatgg ggatattaat

9952861 acctggtttg cctatttcat agaagtgtgg aaaggctta actgggatgc ccactagaaa

9952921 taaaggttt gttattatgt aacattggtc attttctctt ttccttcgcc gggcctgagt

9952981 ttcctcattc aggaatgagg ggattggcta agacaacccc agaggcactt ccagctttgt

9953041 aatggctcct gcgttgcttg ctttttaaa tcacctccta tatgccaggc actgtgccag

9953101 acccttaaa tacaggatat aagacatcaa atatttatat atgtgtgtat atatatgtgt

9953161 gtgtgtatat atatatgtgt gtgtatatat atgtgcatat atgtctgcgt atatatatgt

9953221 gcgtatatat atgcgtatat atatatatat atgtatatat ttgtggtaaa atacacataa

9953281 aaaatttccc attaaagaca tttaataata tttacaatgt tgtgtaacca tcaccactat

9953341 gtagttccag aacattttca ttaccccccc aaaaatcct atacctatta cacagccact

9953401 ccctattctc ccctccctc ggctcttggc aatcactaat ttgtgttagt caagcagaaa

9953461 ttatggattt gctgatttca ttggaatcat aaaatatgtg gccttttgtg tctggctagt

9953521 ttcacttagc ataatgtttt caaggttcac ccataccgta gcatatatca atacttattc

9953581 ctttttatgg ctgaataata ttctcatttg gctgtaccac attttgttta accatgcatc

9953641 agttgatgga catctgcatt gtttctacct tttggctgtt gtgaatagtg ctgctatgaa

9953701 cattgtctac aagttttcgt ttgaacacct gttttccatt cttttgggtc tatatccagt

9953761 agtggaattg gcaggtccta tggcaattcc atgttttact tattgaggaa ctgettttcc

9953821 acagtggtga tgccattttg tattcccacc tgcagtgtgg gaggattcta atttctccac

9953881 atccctgcca acacttgtta taggatgtat ttttagccat atctacccag caagggtatt

9953941 atattccatt gctcagatgc aggaactgat gtatgttaca acaaacctgc agggaaggta

9954001 ttgtcatccc cattttacag atgacaaaac aaagaggttc agagaggtta agtgacttgc

9954061 ccactagatc taccactaga tttgaaccca ggtctctctg cttcccagaa ccatgacccc

9954121 ttccattata cctcatggcc tctccttga tattttcacc gcacgaggaa gggtggagag 
9954181 agacttgagg agggtggtgg gtggggtggg gcatgtttcc caccagccet gccctgtccg

9954241 atcagtGAgA CCCGCCTGGT AgAgGTGCTG GAGGGTGTGT GCAGCAAGTC AGACTTCGAG 9954301 TGCCACCGCC TGCTGGAGCT GAGTGAGGA CTGGTGGAGA GCTGGTGGTT TCACAAgtga

Exon 3

9954361 gtggcaaagg gccttccctg gaagtgggtc acaggtgagq cetggtgata aggcctgatt

E3Rseq

E3R

E4Rseq

E4R
9954421 tggccgagaa gcaggggggt gcatgctggg gcccatgtcc tggttgtgct ccttccaaac

9954481 ccaggtctgc taagaacttg ccgggggact tgcgctccac tttgagcetc agtttaccet

9954541 tctgccaaat ggggaaaggg cattggtcag atggccttt gggtcttatg tccaagctgg

9954601 gttgaatcac agattcaggc atgggggaat ggraacagca cttatgacac tatctcagca

9954661 cetcetccec acctccetcc accetgccec tgcetcagGC AGCAGGAGGC CCCGGACCTC

9954721 TTCCAGTGGC TGTGCTCAGA TTCCCTGAAG CTCTGCTGCC CCGCAGGCAC CTTCGGGCCC

9954781 TCCTGCCTTC gtgagtttt aagttgetct tggggatggg aggggaccac cgagtccagg

9954841 gatccagtcc tggctctgtc cctagttcgc tgtgtgaact caggctactc agataaactt

9954901 ctctggacct cagttcttgc ctgcctgaca gggctgggga gatgggcaaa tcagtgggga

9954961 aaggcttgga gaaagcacag gggctagact gagtcatatg cagtatagtt atcatcatgt

9955021 actaaagaaa tgatagactt cccagccect tcatttccca tgccagatcg gactatggta

9955081 ccttcctggg gaggggcggg tgctgacctg gagcctccat gatcgccatc catcctcaca

9955141 cacagtcctg gcacaagagc tgaacttact accagcctct tttagagcag tctttcctga

9955201 agctacagat aaagagctag ctacaaagat ggcaaattca gtctttgtaa aagaaatat

9955261 tggctgggcg cggtggctca cacctgtaat cccaacactt tgggaggctg cggtgggtgg

9955321 atcatgaggt caggagatcg agaccatcgt ggctatcatg gtgaaacacc gtctctacta

9955381 aaaatacaa aaaattagcc gggcatggtg gcgggcgcct ctagtcccag ctactctgga

9955441 ggctgaggca gaagaatggc atgaacccgg caggcggagc ttgcagtgag ccgagatcat

9955501 gccactgcac tccagcctgg gcgacagagc gagactctgt ctcaaaaaa aaaagaaaa

9955561 tatttggtcc agtggctcgt acctgtaaac ccagcacttt gggaggctga ggcaggagga

9955621 tcacttgagg ccaggagttt gagagaccag cctgggtagt agagcaagac cctgtctctt

9955681 aaaaaaaaa tagtggggca tggtagtgca gcctgttgtt cccctaggct gaggtgggag

9955741 gattgcttga gcccaggagt tcgaagctgc agtgagctat gatcatgtca ttgcctggga

9955801 aacagagcga gaccctgtca ctaaaataa ataaataat aaataataa ataataat

9955861 aataaataa aaggtctgta aatctaatt gttccacaag aggaaattgg ttaagtaaat

9955921 gtcagtttta tgacaaata ttatgtcatt aaaattaatt ttcttctcca aaatgttta

9955981 ctgatatgca gagcagaaaa tattatcttg ttttttttgt ttttttgtct tttttattga

9956041 tcattcttgg gtgtttctcc cagaggggga tttggcaggg tcataggaca atagtggagg

9956101 gaaggtcagc agataaacaa gtgaacaaag gtctctggtt ttcctaggca gaggaccctg

9956161 cggccttccg cagtgtttgt gtccctgggt acttgagatc aaggagtggt gatgactctc

9956221 aaccagcatg ctgccttcaa gcatctgttt aacaaagcac atcttgcacc gccettaatc

9956281 catttaaccc tgagtggaca cagcacatgt ttcagagagc acagggttgg ggataaggtc

9956341 atagatcaac aggatcccaa ggcagaagaa tttttcttag tacagaacaa aatgaaagt

9956401 ctcccgtgtc tacttctttc tacacagaca cagcaaccat ccgatttctc agtgttttcc

9956461 ccactttcc ccctttcta ttccacaaaa ccgccattgt catcctggcc cgttctcaat

9956521 gagctgttgg gtacacctcc cagacggggt ggtggccggg cagagggget cctcacttcc

9956581 cagtaggggc agccgggcag aggcgcccet cacctcccgg acggggcggc tggcegggcg

9956641 gggggetgac cccetcacct ccctcccgga cgggctgget gcceggcgga gacacttctc

9956701 acttcccaga cggggcgget gccgggcgga ggggctcctc acttctcaga cagggcggcc

9956761 gggcagagac getcctcacc tcccagacgg ggtcgcggcc gggcagagac getcctcact

9956821 tcctagatgg gatggcggcc gggcagagac gctcctcact ttccagactg ggcagcctgg
E4F

E4Fseq

Exon 4 
9956881 cagagaggct cctcatatcc cagacgatgg gccgccaggc agagacgctc ctcacttccc 9956941 agacggggtg gtggccgggc agaggctgca atctcggcac tttgggaggc caaggcaggc 9957001 ggctgggagg tggaggttgt agcgagccga gatcacgcca ctgcactcca gcctgggcac 9957061 cattgagcac tgagtgaacg agactccgtc tgcaatcccg gcacctcggg aggccgaggc 9957121 tggcggatca ctcgcgttta ggagctggag accggcccgg ccaacacagc gaaaccccgt 9957181 ctccaccaaa aaatacgaa aaccagtcag gcgtggtggc gcgcgcetgc aatcgcaggc 9957241 actcggcagg ttgaggcagg agaatcaggc agggaggttg cagtgagccg agatggcagc 9957301 agtacagtcc agcttcagct tggcatcaga gggagaccgt gtaaagagag ggagagggag 9957361 accatgggga gagggagagg gaggccatgg ggagagggag agggaaaggg ggagggggag 9957421 gggagggggg gagggaggga aggcaaggga gagggagagg gagagggaga aatattatc 9957481 ttgtatatca aggttgtata gatgacctca cctggtttgg tgtcttccca cagCCTGTCC

9957541 TGgGgGAACA GAgAgGCCCT GCGgtggCtA CGgGCAgtgt GAAgGAgAAg GgACACGAgG 9957601 GgGCAGCGGg CACTGTGACT GCCAAGCCGg CTACGgGgGT GAgGCCTGTg GCCAgtgtgG 9957661 CCTtgGCtAC TtTgAgGCAG AACGCAACGC CAgCCAtCTG GTATGtTCGg gtaggtagc

18 seq
E5Rseq

E6Rseq E5-6R
9957721 aaaaggtgtg gcactgggca ggggcagatg gggcacctgc ctgcccatcc tcatgctgcc 9957781 cccattccac ccagCTTGTT TTGGCCCCTG TGCCCGATGC TCAGGACCTG AgGAATCAAA 9957841 CTGTTTGCAA TGCAAGAAGG GCTGGGCCCT GCATCACCTC AAGTGTGTAG gtaagtgggg 9957901 ccctagctag gtctgggaag atggtcaggg gcctgggctt ggtcctttat tctctcaaca 9957961 caagcctggg ctagactagc ctagtctcca ccttcatgga gatctcaacc tggctgggaa 9958021 ggcagaaaag taaccagata cttacagtcc agtacacagg tactgtgtag tatagtccet 9958081 gtgtacagtg agagatgcct ctgatctagt tcagtggaag tggtgatggg gaatcaggaa 9958141 aggcttcttg gaggaggcgt tactttggcc aagtcctaaa aattgaggaa ggggctgggc 9958201 gcggtggctc acgcctgtaa tcccagcact ttgggaggcc aaggcgggca gatcatgaga 9958261 tcaggagatc gagaccatcc tggctaacat ggtgaaaccc tgtctcaact aaaatacaa 9958321 aaattagct gggcgtggtg gcgggtgcct gtagtcccag ctactcagga ggctgaggca 9958381 ggagaagggc atgaacctgg gaggcggagc ttgcagtgag ccgagatcgc accactgcac 9958441 tccagtctgg gcaacagagg gagactccat ctcaaaaaaa aaaaaaaaa aaaaaaaaa

9958501 tgaggaaggg ttggctagga gaatgaggac actgaacttg gggtcaggaa acctgggttc 995856

995862 9958681 995874 995880

9958861

995892

995898

995904

995910

9959161

99592

995928

9959341

995940

9959461

9959521 aagacttggt ttggtcccag cctagccact tatatagact aaagtaaagg ctaagctgct gtaacaaaa tccccaaaag actgtggctt aaagagtata gaggttggct gggtgtggta gctcactcac gcctctaatc ccagcacttt gagaggctga agtggggtgg atcacctgag gtcaggagtt cgagaccagc ctggccaaca tggcaaaacc ctgtctgtac taaaataca aaatttagc caggcatggt ggcaggtgcc tgtaatccca gctactcggg aggcagaggc aggagagtcg cttgaatcca ggaggcagag gttgcagtga gccaagatca caccattgca ctctagcctg ggtgacaaga gcgaaactcc atctcaaaaa aaaaaaaaag aatctagagg gtagaggttt attttttttt atcatattac agtcccaaag tgagtagtcc aggctggcag gggagctctg ctagtcataa tcattccagt acccagatta ttcctgtaac ttactgcaca atcatcccet tgggcgttgt ctgcatggtt gaagctgagt cctgggcatc tctgtgtccc acatgccagc actcaggaag ggagaaggga aagaaagtgc attgaggagt ccaagcattg ttttaagacc aagctaacgg tggagctcat cactcctgtt tacatcctgt tggccagaac tcaatcacag ggacacactt agcttcaaga caggttggca aatgtggtct ctggctgggc agcctgaagt ccagctagtc tgcttctgtg ttggtagaca gcttgcagtc tctgccatac catttaatcc caggcaagac cattccccaa cggctctggc ttcagcttcc ctactaata gggattgaaa ttctcaccct gctcacctct ctgcagACAT TGATGAGTGT GGCACAGAGG GAGCCAACTG TGGAGCTGAC CAAtTCTGCG TGAACACTGA GgGCTCCTAT GAgtgCCGAg
E5-6F

E5-6Fseq

Exon 5

Exon 6

E7-8-9-F

E7Fseq

14 seq

Exon 7 
9959581 gtcagtgtct acttctgcag aggaggggac gtgaggagtg gaggaagagc tgctccacac 9959641 ctgtccctcc aaaccttccc cttctcaggc ttcagagcac ccccaggcct ccgcttctgg 9959701 agcgtggctc ccctgggcct aggtgcacat ctcaccetca tctttctctc ctctctccag 9959761 ACTGTgCCAA GGCCTGCCTA GgCtGCATGg GgGCAgGgCC AgGtCGCTGt AAgAAgtgtA 9959821 GCCCTGGCTA TCAGCAGGTG GGCTCCAAGT GTCTCGgtga gtctcctget gatgggacac

E8Rseq

E7-8-9R

10 seq

8 seq

E10R
9959881 aggcacctgg gagtgcctca cccagcatga atggtgaaga ggctggaata tgggcaggtg

9959941 ggggaaggaa gggtggaatg ttgcctgggc aagggcagag gggagtgttg agagatggac

9960001 aagatggagt cagggtgctg ggtggggggc cctagcagga ctctgacccc tccetcccet

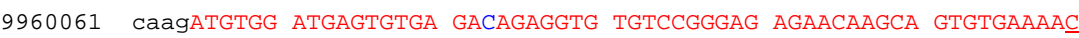

9960121 ACCGAGGGCG GTTATCGCTG CATCTGTGCC GAgGGCTACA AGCAGATGGA AgGCATCTGI

9960181 GTGAAGGAGC AGATCCCAGg tgagccetgg ggcgggagag gggaggtcct cattcaaaga

9960241 gaaggcaggc aagcccettc cccaggtagc agtggcagct ccaggccetg ccccatccet

9960301 actgccaccc agccccctgg aggetgcact gagaccgggc tctacatctg atctccaggt

9960361 tggctctcag cagccttata ccttccaggg tacaaaggga atcagacctg gcatcaaatc

9960421 agtctgcctc cttaacctgt ttcctcatct atccaatggg accagtgttt gccetggcct

9960481 gctgagagct gtcctaggcc gggggtgtgg tgagatgcag ggtaatcaca acgatgatgg

9960541 cagggaccat ttcccCagca attactgtgt cagatgctgt tctagGTGCA TTCCCCATCT

9960601 TAACTGATTT AACCCCTGAA ACAACCCGAC GCTGGAAGTT GGGTTCTCAT CCCCACTCTA

9960661 CAtAtgtaAA AAtgAAgAtg CAgAgAgAtg AAgCtACtTt CCCAgGgCtA tAtggCAAgC

9960721 AAgTCGCAAA GCTGGGAtCC CAATCCAGAC AgTCTGACCG TGGAACGAGA CTCAtACACg

9960781 taataaatgc tctgccccca acttgtccac cacatggcet tggcaagtcc aacccettta

9960841 cctctctgag cctcactttc ccattagtg agacagggat ggtaactgcc ccttgcaggg

9960901 tggttttgag cagtaaatgt agtgtgcctg gcttgctggg caggcctggt ggccatgatg

9960961 atcaggtgtg tgggagttct ggggagactc caagaactac caggaacagg gatacgagtg

9961021 ccaggctgca tctcttgctc ctctgcagAG TCAGCAGGCT TCTTCTCAGA GATGACAGAA

9961081 GACGAgtTGg TGgtGCTGCA GCAgAtgtTC TTtgGCATCA TCATCTGTGC ACtGgCCACG

9961141 CTGGCTGCTA AgGgCGACTT GGTGTTCACC GCCATCTTCA TTGGGGCTGT GGCGGCCATG

9961201 ACTGGCTACT GGTtGTCAgA GCGCAGTGAC CGTGTGCTGG AGGGCTTCAT CAAGgGCAGA

9961261 TAATCGCGGC CACCACCTGT AGGACCTCCT CCCACCCACG CTGCCCCCAG AGCTTGGGCT

9961321 GCCCTCCTGC TGGACACTCA GGACAGCTTG GTTTATTTTT GAGAGTGGGG TAAGCACCCC

9961381 TACCTGCCTT ACAGAGCAGC CCAGGTACCC AGGCCCGGGC AGACAAGGCC CCTGGGgtAA

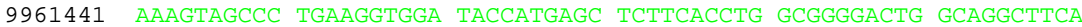

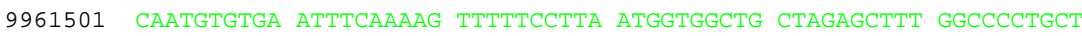

9961561 TAgGAtTAgG TGgtCCTCAC AgGgGtgGgG CCATCACAgC TCCCTCCTGC CAgCTGCATG

9961621 CTGCCAGTTC CTGTTCTGTG TTCACCACAT CCCCACACCC CATTGCCACT TATTTATTCA

9961681 TCTCAgGAAA TAAAgAAAgG tCtTGgAAAg TTAAAAgGCA TCAgtCTtAC TACCtgtCCC

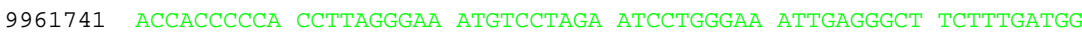

9961801 TGAGTGGAGA AAAGATAgAg GAGAAGGTTG CCCCTGAAGT GCTGTTAGGA GAAGGAGGAT

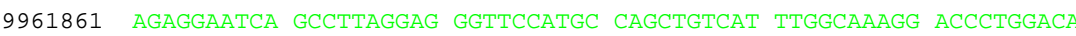

9961921 GATGACTTT GCCTCTGAAC TTCACTCTTC TCTTTCCTCA AATGGGCTTC ATAATGCTTT

9961981 CCACTCAGGC TTAACATGA AATTAAATGA GgTGACAAAT GTGAAGACCT GGACAgtACA

9962041 CAACAGATA TCAATAAAAG TGtGGTCGCC ATtATGACCA GAGCCTCCAA
E8Fseq

Exon 8

Exon 9

E9bE

E10F

Exon 10 
Translation (NP_056328.2 and NP_001070883.1)

MAPWPP KGLVPAMLWGLSLF LNLP GP IWLQP SPPPQSSPPP QP HPCHTCRGLVDSFNKGL ERT IRDNFGGGNTAWEEENLSKYKDSETRLVEVLEGVCSKSDFECHRLLELSEELVESWW FHKQQEAPDLFQWLCSD SLKLCCPAGTFGP SCLPCP GGTERPCGGYGQCEGEGTRGGSGH CDCQAGYGGEACGQCGLGYFEAERNASHLVCSACFGPCARCSGP EESNCLQCKKGWALHH LKCVDIDECGTEGANCGADQFCVNTEGSYECRDCAKACLGCMGAGP GRCKKCSPGYQQVG SKCLDVDECETEVCP GENKQCENTEGGYRCICAEGYKQMEGICVKEQIPESAGFF SEMTE DELVVLQQMFFGI I ICALATLAAKGDLVFTAIF I GAVAAMTGYWLSERSDRVLEGF IKGR $\mathrm{X}$ 